\title{
Development of a displacement-based design approach for modern mixed RC-URM wall structures
}

\author{
Alessandro Paparo ${ }^{\mathrm{a}}$ and Katrin Beyer ${ }^{*}$ \\ Earthquake Engineering and Structural Dynamics (EESD), School of Architectural, Civil and Environmental \\ Engineering (ENAC), École Polytechnique Fédérale de Lausanne (EPFL), 1015 Lausanne, Switzerland
}

(Received July 29, 2014, Revised June 1, 2015, Accepted June 8, 2015)

\begin{abstract}
The recent re-assessment of the seismic hazard in Europe led for many regions of low to moderate seismicity to an increase in the seismic demand. As a consequence, several modern unreinforced masonry (URM) buildings, constructed with reinforced concrete (RC) slabs that provide an efficient rigid diaphragm action, no longer satisfy the seismic design check and have been retrofitted by adding or replacing URM walls with RC walls. Of late, also several new construction projects have been conceived directly as buildings with both RC and URM walls. Despite the widespread use of such construction technique, very little is known about the seismic behaviour of mixed RC-URM wall structures and codes do not provide adequate support to designers. The aim of the paper is therefore to propose a displacement-based design methodology for the design of mixed RC-URM edifices and the retrofit of URM buildings by replacing or adding selected URM walls with RC ones. The article describes also two tools developed for estimating important quantities relevant for the displacement-based design of structures with both RC and URM walls. The tools are (i) a mechanical model based on the shear-flexure interaction between URM and $\mathrm{RC}$ walls and (ii) an elastic model for estimating the contribution of the RC slabs to the overturning moment capacity of the system. In the last part of the article the proposed design method is verified through nonlinear dynamic analyses of several case studies. These results show that the proposed design approach has the ability of controlling the displacement profile of the designed structures, avoiding concentration of deformations in one single storey, a typical feature of URM wall structures.
\end{abstract}

Keywords: displacement-based design; modern mixed reinforced concrete-unreinforced masonry wall structures; seismic design; pushover analyses; inelastic time history analyses

\section{Introduction}

In recent years, many modern unreinforced masonry (URM) buildings, which have been constructed with reinforced concrete (RC) slabs, have been retrofitted by adding RC walls to the existing structure or by replacing selected URM walls with RC ones (Magenes 2006, Cattari and Lagomarsino 2013). If the RC members are designed to withstand larger displacement demands than URM walls, experimental and numerical studies have shown that this retrofit technique can

*Corresponding author, Professor, E-mail: katrin.beyer@epfl.ch

aPh.D., E-mail: alessandro.paparo@epfl.ch

Copyright $\odot 2015$ Techno-Press, Ltd.

http://www.techno-press.org/journals/eas\&subpage=7

ISSN: 2092-7614 (Print), 2092-7622 (Online) 
substantially increase the displacement capacity of the system (Paparo and Beyer 2014, 2015). Of late, also new buildings have been designed directly as mixed RC-URM wall structures since structures with URM walls only would not pass the classical force-based design check.

Mixed RC-URM construction varies significantly from region to region (Magenes 2006, Cattari and Lagomarsino 2013) and this paper is limited to modern mixed RC-URM systems that are representative of residential buildings for countries of low to moderate seismicity in central Europe. These systems are characterised by the following features:

- The RC-URM buildings are modern edifices of three to five storeys and the masses are evenly distributed over the height.

- The RC and URM walls are continuous over the height and connected at each floor by 20 to $30 \mathrm{~cm}$ thick RC slabs that provide an efficient rigid diaphragm action.

- The length of the RC walls varies between 2 and $5 \mathrm{~m}$ and their aspect ratios is within 1.5 and 3. The RC walls are 20 to $30 \mathrm{~cm}$ thick and designed according to modern codes to develop a flexural behaviour with displacement capacities larger than those of URM walls. The mean concrete cylinder compressive strength at 28 days is between 20 and $50 \mathrm{MPa}$ and the reinforcement bars have mean yield strengths between 500 and $600 \mathrm{MPa}$. The total longitudinal reinforcement ratio of the RC walls varies between $0.2 \%$ and $4.0 \%$ (EN 1992-1 2004). In the RC slabs the longitudinal reinforcement ratio varies between $0.13 \%$ and $4.0 \%$ (EN 1992-1 2004).

- The URM walls have lengths up to $7 \mathrm{~m}$ and aspect ratio in the range of 0.5 and 3 . The URM walls always outnumber the RC ones and are built with hollow clay 20 to $30 \mathrm{~cm}$ thick bricks in combination with standard cement mortar. URM walls are characterised by mean masonry compressive strengths $\left(f_{c M}\right)$ between 4 and $8 \mathrm{MPa}$ and axial stress ratios $\left(\sigma_{0} / f_{c M}\right)$ between 0.05 and 0.25 .

Despite the popularity of these constructions, research efforts have been directed only recently towards developing seismic design methodologies for mixed RC-URM wall buildings. As a consequence, codes do not provide guidelines for such mixed structures (Magenes 2006) and design engineers have generally designed them using oversimplified assumptions. Noting the importance of such buildings and, at same time, the lack of guidelines, the principal objective of this investigation is to develop a displacement-based design (DBD) methodology for the design of mixed RC-URM wall structures and the retrofit of URM buildings by replacing or adding selected URM walls by RC ones. The methodology follows the direct DBD (DDBD) approach by Priestley et al. (2007) and consists of three main phases:

(i) A preliminary DDBD check of the plain URM building.

(ii) If the structure does not satisfy the seismic design requirements and shows a dominant shear behaviour, a mixed structural system with improved behaviour is devised by replacing the critical URM wall or walls with RC ones. If the URM walls show a dominant rocking behaviour, adding RC walls will increase the strength but not the displacement capacity.

(iii) The DDBD design of the mixed RC-URM wall structure is carried out. Several aspects concerning the interaction between RC and URM walls are evaluated by using a mechanical model which represents the URM walls with an equivalent shear beam and the RC walls with an equivalent flexural cantilever. At the end of the procedure, guidelines for the design of the RC members and the out-of-plane check of the URM walls are briefly outlined.

As the mechanical model represents these mixed buildings close to failure (see Section 3), the proposed DDBD approach can be used for the design of systems which are expected to attain, according to EN 1998-3 (2005), the significant damage (SD) limit state. Furthermore, as the article focuses on the in-plane interaction between RC and URM walls, the possible formation of out-of- 
plane mechanisms is not examined. Investigations on the out-of-plane behaviour of systems with RC and URM walls have been carried out by Tondelli and Beyer (2014). In addition, to simplify matters, possible sources of uncertainty are neglected (for instance, uncertainty in the deformation capacity of the URM walls is not accounted for).

Section 2 introduces features of this typology of mixed systems relevant for DDBD and outlines how the displacement capacity of such structures has been evaluated. The section is then followed by a description of the mechanical model that represents the effects of the interaction between RC and URM walls. Sections 4 to 6 introduce the concepts of the DDBD approach and develop its application for mixed RC-URM wall structures. The algorithm is then applied to a set of case studies and validated against results from inelastic time-history analyses (Section 7). The article closes with a summary of the main findings and an appendix with a design example.

\section{Features of mixed RC-URM walls structures}

In this section, features of mixed RC-URM walls structures relevant for DDBD are introduced with the following objectives:

(i) To define the design displacement profile that will be adopted in DDBD;

(ii) To define for which cases the interaction between URM and RC walls may improve the structural behaviour;

(iii) To set the design drift limits that will be adopted.

Under lateral loading, shear dominated URM wall buildings display concave displacement shapes as illustrated in Fig. 1(a). On the other hand, the displacement profiles of slender RC wall are convex when struck by an earthquake, Fig. 1(b). Consequently, as represented in Fig. 1(c), it seems reasonable to assume a global linear design displacement profile when RC and URM walls are coupled together. Indeed, Section 3 will show that such an assumption can be controlled during the DDBD process by varying the strength and stiffness of the RC walls.

The same behaviour was described by Paulay and Priestley (1992) for dual frame-wall buildings. Slender wall elements, which show mainly flexural deformations, are coupled to frames, whose global behaviour can be approximated by that of a shear beam. As a result, and similarly to

(a)

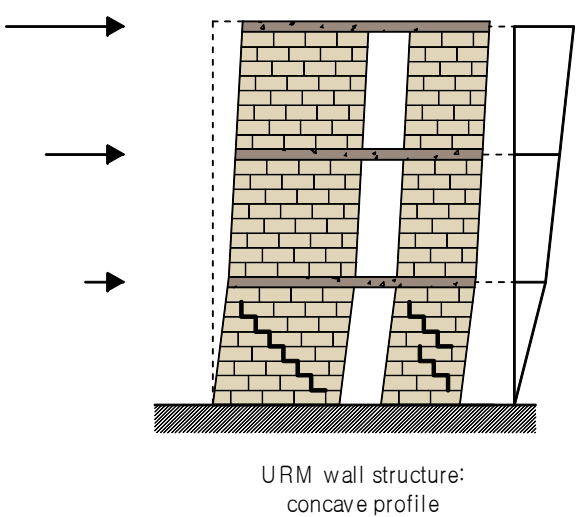

(b)

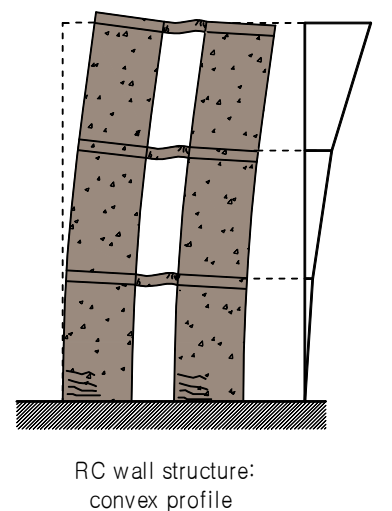

(c)

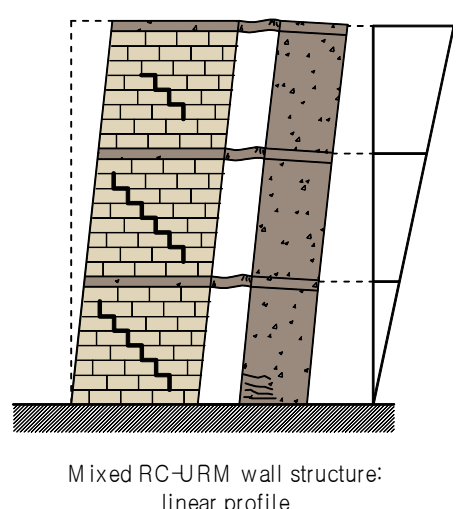

Fig. 1 URM (a), RC (b) and mixed RC-URM wall (c) structures: deflected shapes and displacement profiles 
mixed RC-URM wall buildings, the deformed shape of dual frame-wall buildings tends to be linear over the height of the building.

If the masonry walls have a dominant rocking response, they will exhibit a linear or slightly convex deformation profile and less benefit is gained by coupling RC walls with URM walls. However, due to the significant out-of-plane stiffness and strength of the RC slabs (Lang 2002) and the resulting moment restraint at each floor level, a shear critical behaviour of the URM walls is very common in such mixed systems.

For this typology of modern mixed structures, the RC members are designed to exhibit larger displacement capacities than those relative to URM walls. As a consequence, the SD limit state is always controlled by the URM walls since they attain the limit state before the RC members (Paparo and Beyer 2014, 2015). In the following, the SD limit state is considered attained when the first URM wall reaches its inter-storey drift capacity (Paparo and Beyer 2015) that is set equal to $0.4 \%$ for walls with dominant shear behaviour and $0.8 \% H_{C F} / L$ for walls with dominant rocking behaviour (EN1998-3 2005). $H_{C F}$ and $L$ are the height of contra-flexure point and the length of the wall, respectively. The inter-storey drift $\delta$ is calculated as the relative horizontal displacement between the beams underneath and above the selected storey $\left(\Delta_{i}\right.$ and $\left.\Delta_{j}\right)$ divided by the storey height $h$

$$
\delta=\frac{\Delta_{i}-\Delta_{j}}{h}
$$

\section{Shear-flexure cantilever model}

The interaction between shear and flexural dominated systems has been studied over the last 50 years and several methods for analysing dual frame-wall systems have been proposed. One of these is the so-called "shear-flexure cantilever", which treats walls and frames as flexural and shear cantilevers respectively (e.g., Chiarugi 1970, Rosman 1974, Pozzati 1980, Smith and Coull 1991). Given the similarities of mixed RC-URM wall buildings to dual frame-wall structures, the shear-flexure cantilever model is extended for analysing such structures. The objective is to develop a simple tool able (i) to check the displacement profile of mixed RC-URM wall structures and (ii) to evaluate the height of the contra-flexure point of the RC walls $\left(H_{C F, R C}\right)$. Both parameters will be used in the DDBD process presented in Section 6.

After the description of the mechanical model (Section 3.1) and the comparison of several results against numerical simulations (Section 3.2), charts which can be directly used during the DDBD procedure are presented (Section 3.3).

\subsection{Differential equations of the shear-flexure cantilever model}

The interaction between RC and URM walls can be described with a simple mechanical model which consists of a pure bending cantilever, representing the RC walls, and a pure shear cantilever, which describes the URM walls. The two beams are continuously connected over the height by axially rigid links with zero moment capacity, Fig. 2.

The differential equations for a shear-flexure cantilever have been first set up and solved by Rosman (1967) and the following work is based on the textbook by Pozzati (1980). At any cross section at height $x$, the drift $\theta(x)$ can be calculated as the ratio between the shear carried by the 
shear cantilever, $V_{1}(x)$, divided by its shear stiffness GA

$$
\theta(x)=\frac{d v(x)}{d x}=\frac{V_{1}(x)}{G A}
$$

where $v(x)$ is the horizontal displacement of the system. The shear $V_{1}(x)$ is the derivative of the moment carried by the shear cantilever $M_{1}(x)$ with respect to $x$. Its derivative can be written as

$$
\frac{d^{2} v(x)}{d x^{2}}=\frac{1}{G A} \frac{d^{2} M_{1}(x)}{d x^{2}}
$$

At any height, the ratio $\frac{1}{G A} \frac{d^{2} M_{1}(x)}{d x^{2}}$ of the shear cantilever has to be equal to the curvature of the flexural beam. Given $\operatorname{OTM}(x)$ the overturning moment introduced by the external forces and $M_{2}(x)$ the moment carried by the flexural beam, it therefore follows

$$
\frac{1}{G A} \frac{d^{2} M_{1}(x)}{d x^{2}}=-\frac{1}{E I} M_{2}(x)=-\frac{1}{E I}\left(O T M(x)-M_{1}(x)\right)
$$

The general solution of Eq. (4) is

Shear beam:

Flexure beam:

$$
M_{1}(x)=A \cosh \left(\alpha \frac{x}{H}\right)+B \sinh \left(\alpha \frac{x}{H}\right)+M_{t p}(x)
$$

where $\alpha$ is the stiffness ratio of the shear and flexural beam and is obtained as

$$
\alpha=H \sqrt{\frac{G A}{E I}}
$$

where $E I$ is the sum of the flexural stiffnesses of the concrete walls and $G A$ is the sum of the shear stiffnesses of the masonry walls. In Eq. (5a) $M_{t p}(x)$ is the particular solution which, for constant horizontal load $q$, takes the following form

$$
M_{t p}(x)=\operatorname{OTM}(x)-q\left(\frac{H}{\alpha}\right)^{2}
$$

In Section 3.3 the limitations related to the adoption of the constant load pattern will be discussed. The two constants $A$ and $B$ of Eq. (5a) are found by assigning two boundary conditions. In literature the shear-flexure cantilever was used to solve the elastic behaviour of dual structures. Hence, the equations were solved for boundary conditions where $(i)$ the moment at the top of the shear cantilever is zero and that (ii) the rotation at the base of the flexure cantilever is zero, which implies that the flexure cantilever is fixed at the bottom. For the mixed RC-URM wall structure at SD limit state the equations need to be solved for different boundary conditions, which will be discussed in the following.

Since the model aims to represent the structure attaining SD limit state, it is expected that the $\mathrm{RC}$ walls yield. In order to account for the formation of the plastic hinge at their base, the flexural cantilever is modelled with a pinned base condition. A base moment, corresponding to the total 


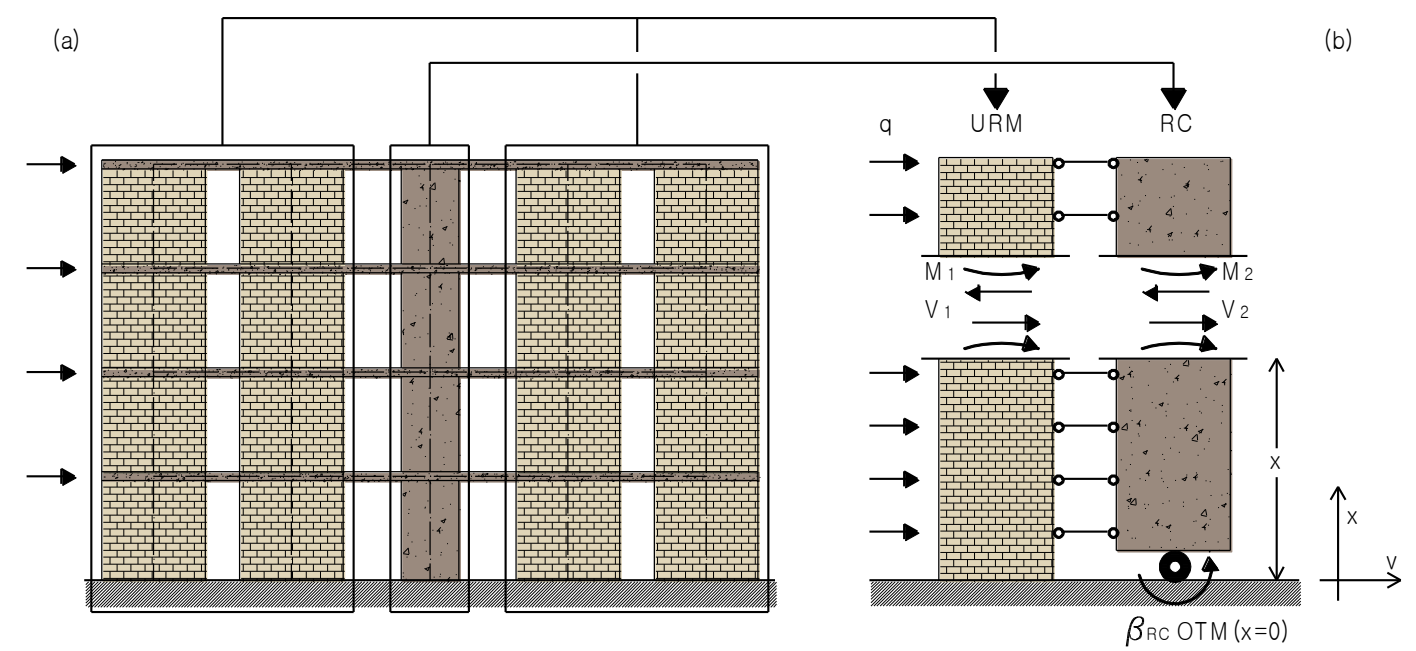

Fig. 2 Mechanical model: identification of shear (URM) and flexural (RC) walls (a); definition of the reference system and of the internal forces (b)

flexural capacity of the RC walls, is then applied as external moment to the hinge in addition to the externally applied horizontal load $q$. The parameter $\beta_{R C}$ describes the ratio between the base moment $M_{2}(x=0)$ provided by the flexural (RC) wall and OTM( $\left.x=0\right)$

$$
\beta_{R C}=\frac{M_{2}(x=0)}{O T M(x=0)}
$$

The second constant can be derived by setting the moment at the top of the shear beam equal to zero: $M_{1}(x=H)=0$. The shears $V_{1}(x)$ and $V_{2}(x)$ are found as the derivate of $M_{1}(x)$ and $M_{2}(x)$ with respect to $x$. By analytically integrating the drift $\theta(x)$ between the base $(x=0)$ and the height of the floor $\left(x=h_{i}\right)$, the horizontal displacement $v_{i}$ of each storey is calculated

$$
v_{i}=\int_{0}^{h i} \theta(x) d x
$$

\subsection{Comparison of the results of the shear-flexure cantilever model against numerical simulations}

For several configurations of mixed RC-URM wall structures, the inter-storey drift predicted by the shear-flexure cantilever model is compared to the one obtained by pushover analyses. The objective is to check the influence of four parameters on the displacement profile and on the height of the contra-flexure point of the RC wall. The parameters are: (i) number of storeys, (ii) number of URM walls, (iii) length of URM walls and (iv) longitudinal reinforcement ratio of the RC slabs. Table 1 shows the combination of the four variables.

Fig. 3 represents the elevation of the 4-storey layout configurations. The thickness of the walls is always $0.20 \mathrm{~m}$ and the clear storey height of the walls is always $2.8 \mathrm{~m}$. The length of the RC walls is fixed to $3.30 \mathrm{~m}$. The moment capacities at the base of the RC walls, $M_{2}(x=0)$, are $1600 \mathrm{kNm}, 1700 \mathrm{kNm}$ and $1800 \mathrm{kNm}$ for the 3,4 and 5 storey configurations, resulting in values 

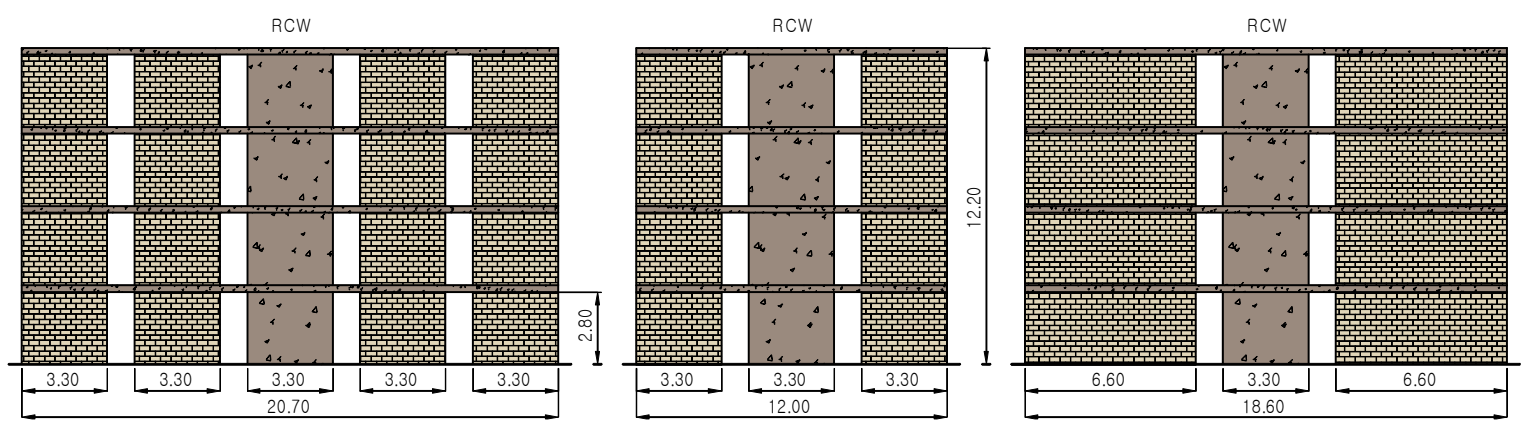

Fig. 3 Layouts1, 2 and 3 (4-storey configurations). All dimensions in $\mathrm{m}$

Table 1 Parameters investigated to compare the shear-flexure cantilever model against numerical simulations

\begin{tabular}{ccccc}
\hline \hline & $\begin{array}{c}\text { Number of storeys } \\
{[-]}\end{array}$ & $\begin{array}{c}\text { Number of URM } \\
\text { walls } \\
{[-]}\end{array}$ & $\begin{array}{c}\text { Length of URM } \\
\text { walls } \\
{[\mathbf{m}]}\end{array}$ & $\begin{array}{c}\text { Longitudinal reinforcing } \\
\text { bars of RC beams } \\
{\left[\mathbf{m m}^{\mathbf{2}}\right]}\end{array}$ \\
\hline Layout 1 & $3,4,5$ & 4 & 3.30 & $500-750$ \\
Layout 2 & $3,4,5$ & 2 & 3.30 & $500-750$ \\
Layout 3 & $3,4,5$ & 2 & 6.60 & $500-750$ \\
\hline
\end{tabular}

of $\beta_{\mathrm{RC}}$ between $16 \%$ and $34 \%$. The transverse reinforcements of the RC members are designed to prevent shear failure. As two-dimensional analyses are carried out, the slabs are represented by RC beams with a cross section of $0.25 \times 0.60 \mathrm{~m}$. The effective width of $0.60 \mathrm{~m}$ corresponds to three times the wall width (Priestley et al. 2007). The free span of the RC beams is equal to $1.05 \mathrm{~m}$ and the area of their longitudinal reinforcement is varied between 500 and $750 \mathrm{~mm}^{2}\left(\rho_{C B}=0.38 \%\right.$ $0.57 \%$ ). The two reinforcement ratios correspond, approximately, to longitudinal reinforcing bars D10 every $110 \mathrm{~mm}\left(\rho_{C B}=0.38 \%\right)$ and D12 every $90 \mathrm{~mm}\left(\rho_{C B}=0.57 \%\right)$. Finally, the masses, which are constant per storey, are proportional to the length of the walls. It results that the storey masses are equal to $35.7 \mathrm{t}$ for layout 1 and 3 and $21.4 \mathrm{t}$ for layout 2. Sections 3.2.1 and 3.2.2 describe the mechanical and geometrical properties adopted for the shear-flexure cantilever model and the pushover analyses and Section 3.2.3 compares the results obtained from the two different approaches.

\subsubsection{Mechanical and geometrical properties for the shear-flexure cantilever model}

The mechanical model aims to represent the interaction between URM and RC walls by means of an ideal shear and an ideal flexure cantilever which have constant stiffnesses $G A$ and $E I$ along their height (Section 3.1). In this section, analogies and differences between the seismic behaviour of mixed RC-URM structures obtained from experimental campaigns (Paparo and Beyer 2014, Beyer et al. 2015) and the hypotheses of the mechanical model are discussed. Based on this comparison, recommendations for setting up the shear-flexure cantilever model are formulated.

(i) In the experimental campaigns it was observed that in the URM walls the shear cracks are distributed over the height of the building. Hence, the stiffness of the shear beam can be based on the cracked stiffness GA of the masonry walls. According to EN 1998-3 (2005), GA is assumed as half of the uncracked stiffness of the masonry walls. 
Table 2 Mechanical and geometrical properties adopted for the shear-flexure cantilever model

\begin{tabular}{ccccc}
\hline & \multicolumn{2}{c}{ Shear beam (URM walls) } & \multicolumn{2}{c}{ Flexural beam (RC walls) } \\
\cline { 2 - 5 } & $\begin{array}{c}\boldsymbol{A} \\
{\left[\mathbf{m}^{2}\right]}\end{array}$ & $\begin{array}{c}\boldsymbol{G} \\
{[\mathbf{G P a}]}\end{array}$ & $\begin{array}{c}\boldsymbol{I} \\
{\left[\mathbf{m}^{4}\right]}\end{array}$ & $\begin{array}{c}\boldsymbol{E} \\
{[\mathbf{G P a}]}\end{array}$ \\
\hline Layout 1 & 2.20 & 0.265 & 0.599 & 36.0 \\
Layout 2 & 1.10 & 0.265 & 0.599 & 36.0 \\
Layout 3 & 2.20 & 0.265 & 0.599 & 36.0 \\
\hline
\end{tabular}

$A$ : sum of the shear areas of the masonry walls

$G$ : cracked shear stiffness of the masonry walls from Paparo and Beyer (2015)

I: sum of the moment of inertia of the uncracked RC walls

$E$ : elastic modulus of the concrete

(ii) The experimental tests have shown that the cracks in the RC walls are concentrated in the first storey, resulting in a stiffness of the first storey which is lower than the stiffness of the upper storeys. In order to find closed form solutions for the mechanical model, the flexure beam has to be assigned a constant stiffness $E I$ over the height of the building. To account for the reduced stiffness of the first storey, the flexure beam is pinned at the base and a moment equal to the yield moment of the wall is applied.

(iii) From the dynamic test (Beyer et al. 2015) it was observed that in the top storeys the URM walls feature significant rocking deformations. As the URM walls are only represented by a shear beam, this rocking deformation is not accounted for and the mechanical model overestimates for the top storeys the influence of the shear cantilever on the displacement profile (see also Section 3.2.3). To compensate this effect, the stiffness of the flexural beam $E I$ is based on gross sectional properties, without considering a reduction factor to account for the small construction-joint cracks which develop between RC walls and slabs in the top storeys. Table 2 summarises the mechanical and geometrical properties adopted for the shear-flexure cantilever models.

\subsubsection{Mechanical and geometrical properties for the numerical simulations}

To validate the results from the shear-flexure cantilever model, numerical simulations are carried out using the software TREMURI (Largomarsino et al. 2013). The structure is modelled as a 2D equivalent frame where the elements representing URM and RC walls are connected at the storey heights by RC beam elements representing the RC slabs. The macro-element developed by Penna et al. (2013) is used for the masonry walls. Such an element is representative of a storeyhigh masonry panel and allows, by means of a relation between average stresses and average strains, to represent the two main in-plane failure mechanisms (i.e., shear and bending-rocking). Timoshenko beams with plastic hinges at their extremities, whose hysteretic behaviour is characterised by the Takeda model, represent RC members. For further details of the software, the reader is referred to Penna et al. (2013), Lagomarsino et al. (2013).

Concerning the adopted material properties and the construction of the equivalent frame, the indications proposed by Paparo and Beyer (2015) are followed. Table 3 resumes the assumed mechanical properties: $c_{e q}$ and $\mu_{e q}$ are the equivalent friction and cohesion parameters of the macro-element (Penna et al. 2013) resulting from the homogenization technique. They are calculated by assigning half of the shear strength $V_{s h}$ to the friction component $V_{\mu}$ and half of the shear strength to the cohesion component $V_{c}$ (Paparo and Beyer 2015). 
According to Penna et al. (2013), $V_{s h}$ can be estimated on the basis of the strength criterion which is representative of the expected failure. In this case, the strength of the masonry walls is calculated according to Mann and Müller (1982). If the material properties of the URM walls are not known, an alternative for calculating the shear strength $V_{s h}$ of a masonry wall is proposed by Priestley et al. (2007). Given $N$ the axial force on section, $V_{s h}$ can be predicted as

$$
\begin{gathered}
V_{s h}=\mu_{m} N+c_{m} A_{\text {eff }} \\
V_{s h} \approx 0.46 N
\end{gathered}
$$

In Eq. (10a) the parameters $\mu_{m}$ and $c_{m}$ have the meaning of global strength parameters and $A_{\text {eff }}$ is the effective un-cracked section. Eq. (10b) is an approximation of Eq. (10a) and results from the assumption of $\mu_{m}=0.4$ (global friction) and $c_{m} / f_{c M}=0.05$ (global cohesion over compressive strength of the masonry wall). $A_{\text {eff }}$ is calculated taking into account the wall cracking due to flexure (Priestley et al. 2007).

\begin{tabular}{|c|c|c|}
\hline Materials & Material properties & Macro-model \\
\hline \multirow{9}{*}{ URM members } & $\boldsymbol{\mu} *[-]$ & 0.19 \\
\hline & \multirow{3}{*}{$c^{*}[\mathrm{MPa}]$} & 0.06 (three storeys) \\
\hline & & 0.08 (four storeys) \\
\hline & & 0.10 (five storeys) \\
\hline & $f_{m}[\mathrm{MPa}]$ & 6.30 \\
\hline & $E_{m x}[\mathrm{GPa}]$ & 5.10 \\
\hline & $G_{m}[\mathrm{GPa}]$ & 0.53 \\
\hline & $G c_{t}[-]$ & 1.00 \\
\hline & $\beta[-]$ & 0.10 \\
\hline \multirow{5}{*}{ RC members } & \multirow{2}{*}{$E_{c}[\mathrm{GPa}]$} & $E_{e}\left(1^{\text {st }}\right.$ storey walls $\&$ beams $)$ \\
\hline & & 18.00 (above storey walls) \\
\hline & \multirow{2}{*}{$G_{c}[\mathrm{GPa}]$} & $E_{e} / 2.40\left(1^{\text {st }}\right.$ storey walls $\&$ beams $)$ \\
\hline & & 7.50 (above storey walls) \\
\hline & $f_{y}[\mathrm{MPa}]$ & 550 \\
\hline
\end{tabular}

Table 3 Mechanical properties adopted for the numerical simulations

$\mu^{*}$ and $c^{*}$ : equivalent friction and cohesion coefficients

$f_{m}$ : masonry compressive strength

$E_{m x}$ : E-modulus of masonry panels subjected to compression orthogonal to bed-joints

$G_{m}=\left(0.25 E_{m x}\right) /\left(2 \cdot\left(1+v_{M}\right)\right):$ masonry shear modulus

$v_{M}$ : Poisson ratio of the masonry wall

$G c_{t}$ : parameter for the non-linear plastic deformation in the pre-peak response (shear-damage behaviour of the URM walls)

$\beta$ : parameter for the non-linear plastic deformation in the post-peak response (shear-damage behaviour of the URM walls)

$E_{c}$ and $G_{c}$ : RC member's Young's and shear modulus

$f_{y}$ : reinforcing bar yield strength adopted in RC members

Differently from the mechanical model, TREMURI can account explicitly for the stiffness 
variation over the height of the RC walls by assigning different stiffnesses from one storey of the $\mathrm{RC}$ walls to another. The first storeys of the RC walls are assigned the effective stiffness $E I_{e}$ and the storeys above the first one are assigned one half of the gross sectional uncracked stiffness. The $50 \%$ of reduction of the gross sectional uncracked stiffness is to account for the small construction-joint cracks that develop between RC walls and slabs (Paparo and Beyer 2015) and is considered applicable if the minimum mean longitudinal reinforcement ratio of the $\mathrm{RC}$ walls is larger than $0.2 \%(0.2 \%$ is the minimum longitudinal reinforcement ratio for $\mathrm{RC}$ walls according to EN 1992-1 (2004)). Additionally, also the RC beams are assigned the effective stiffness $E I_{e}$.

The effective stiffness $E I_{e}$ corresponds to the nominal moment $M_{N}$ divided by the yield curvature $\varphi_{y}$ [Priestley et al. 2007]. $M_{N}$ is calculated considering the axial force acting at the base of the wall under gravity loads only, and $\varphi_{y}$ is the nominal yield curvature, which is equal to $C \varepsilon_{y} / l_{w}$. $C$ is a constant that depends on the geometrical properties of the section; for rectangular RC walls Priestley et al. (2007) recommends $C=2.00 . \varepsilon_{y}$ is the yield strain of the longitudinal reinforcing bars and $l_{w}$ is the wall length.

\subsubsection{Validation of the shear-flexure cantilever model}

In order to gauge the ability of the shear-flexure cantilever model to predict the displacement profile of a mixed RC-URM wall structure, the inter-storey drift profiles calculated by the shearflexure cantilever model ("cantilever model") are compared with drift profiles obtained from the TREMURI pushover analyses ("TREMURI", Fig. 4). The mechanical model aims at representing the structure with its properties at the SD limit state (see Sections 3.1 and 3.2.1). Hence, the drift profiles computed with the mechanical model are benchmarked against the TREMURI profiles for which an inter-storey drift demand of $0.4 \%$ is first attained (SD limit state for URM walls failing in shear, see Section 2). For the comparison of the two approaches, the drift profiles are normalised to the maximum inter-storey drift attained over the height of the systems, as the mechanical model does not provide information on the magnitude of the inter-storey drifts but just on the shape of the profiles.

Fig. 4 shows that the mechanical model estimates the inter-storey drift profile obtained from the TREMURI analyses rather well. For the two lowest storeys, the difference between the two predictions is generally small, while for the upper storeys the discrepancy increases. As outlined in Section 3.2.1, the mechanical model does not account for the rocking behaviour of the URM walls, which is likely to take place in the upper storeys because of the low axial force acting on the URM walls. As a result, the mechanical model overestimates the restraining action provided by the URM walls in the upper levels and therefore underestimates the drifts in the upper storeys.

In addition, the mechanical model leads to a good estimation of the height of contra-flexure point of the RC walls $H_{C F R C}$ (Fig. 4, horizontal lines). Using the mechanical model, $H_{C F, R C}$ can be calculated by setting in Eq. (5b) $M_{2}(x)$ equal to zero and solving for $x$. For the pushover analyses, $H_{C F, R C}$ is computed as the ratio between the base moment and the base shear carried by the RC wall.

\subsection{Application of the shear-flexure cantilever model}

This section presents charts (Fig. 5) that will be used in the DDBD process to check if the displacement profile of the mixed structure can be assumed as linear. The charts summarise the results of a parametric study, carried out with the shear-flexure cantilever model, in which three parameters are investigated: (i) the number of storeys $n$; (ii) the mechanical ( $E$ and $G$ ) and 
geometrical $(H, I$ and $A)$ characteristics of the URM and RC walls, which are combined in the stiffness ratio $\alpha$; (iii) the strength repartition between the different structural systems, which are expressed by the $\mathrm{RC}$ wall strength ratio $\beta_{R C}$.

The solid lines in Fig. 5 show, for different values of $n, \alpha$ and $\beta_{R C}$, the ratio $R_{\delta}=\delta_{1} / \delta_{2}$ that is obtained from the mechanical model, where $\delta_{1}$ and $\delta_{2}$ are the inter-storey drifts of the first and second storey. The inter-storey drifts of the upper storeys are not explicitly considered for the following reasons: (i) $\delta_{1}$ and $\delta_{2}$ are particularly well predicted by the mechanical model (Fig. 4); (ii) the pushover analyses carried out in Section 3.2.3 showed that the displacement profile is
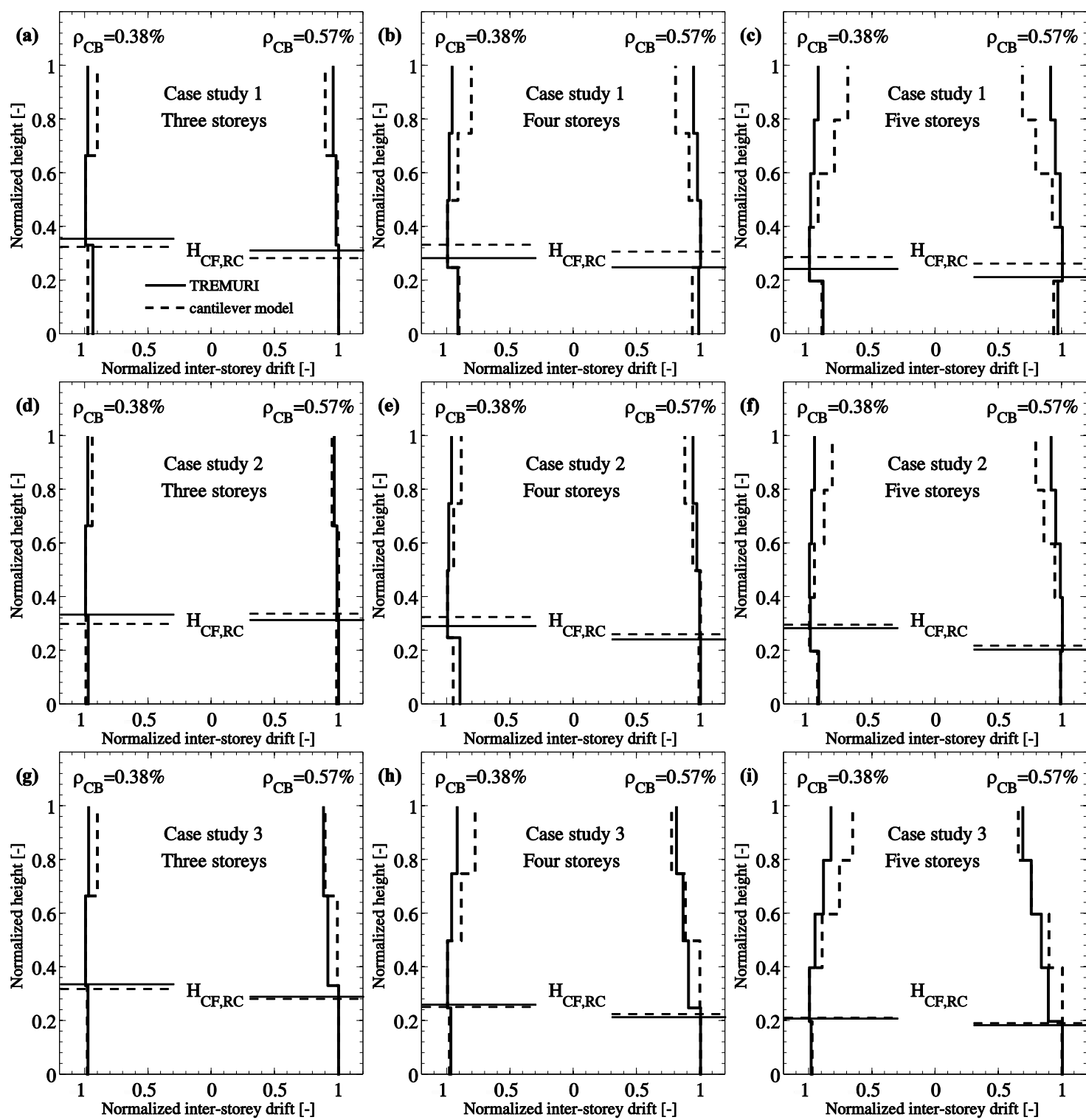

Fig. 4 Normalized inter-storey drifts and normalized height of contra-flexure points in the RC walls $H_{C F, R C}$ 

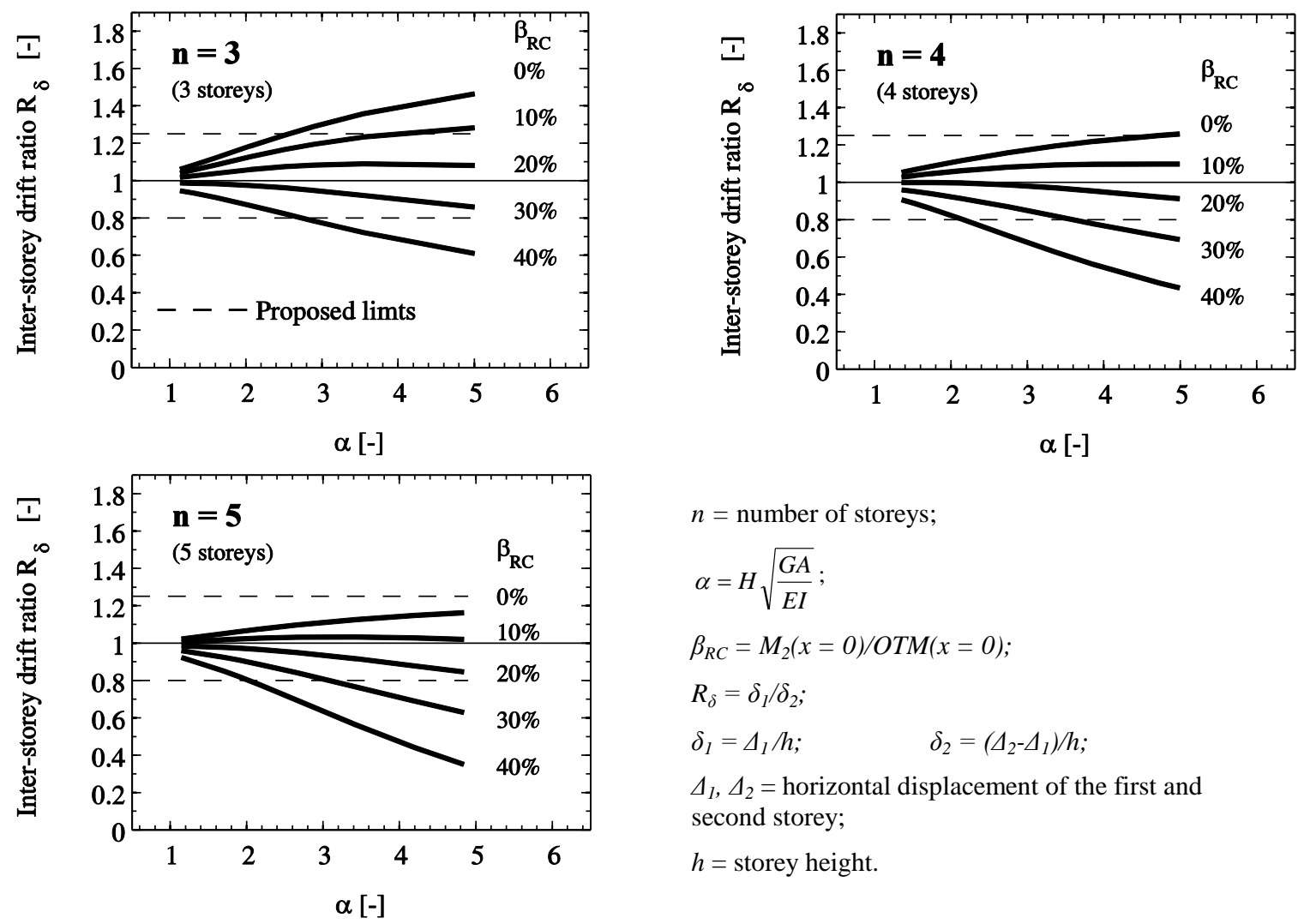

$n=$ number of storeys;

$\alpha=H \sqrt{\frac{G A}{E I}} ;$

$\beta_{R C}=M_{2}(x=0) / O T M(x=0)$;

$R_{\delta}=\delta_{1} / \delta_{2} ;$

$\delta_{1}=\Delta_{1} / h$;

$\delta_{2}=\left(\Delta_{2}-\Delta_{1}\right) / h$

$\Delta_{1}, \Delta_{2}=$ horizontal displacement of the first and second storey;

$h=$ storey height.

Fig. 5 Influence of the parameters $n, \alpha$ and $\beta_{R C}$ on the inter-storey drift ratio $R_{\delta}$. Proposed limits for considering a linear the displacement profile of the structure

approximately linear over the entire height of the building if $R_{\delta}$ is close to one (Fig. 4).

It is proposed that the assumption of a linear displacement profile can be considered valid, if the ratio $R_{\delta}$ of first to second storey drifts that is predicted by the mechanical model takes a value between 0.80 and 1.25

$$
R_{\delta}=\frac{\delta_{1}}{\delta_{2}} \in[0.80-1.25]
$$

The charts in Fig. 5 are derived by assuming a horizontal load $q$ constant over the height of the shear-flexure cantilever (Section 3.1). Provided that the masses are constant over the height of the building, the mechanical model therefore assumes that the structure is subjected to an acceleration profile that is also constant over the height. In order to check the actual acceleration profile, dynamic analyses are carried out with TREMURI. The results, plotted in Fig. 6, show that:

(i) The most appropriate acceleration profile would be bi-linear (i.e., constant over the two bottom storeys and linearly increasing over the storeys above-see grey lines in Fig. 6).

(ii) The constant and inverted triangular acceleration profiles, represented in Fig. 6 with solid and dashed black lines, are bounds of the actual acceleration profile. 

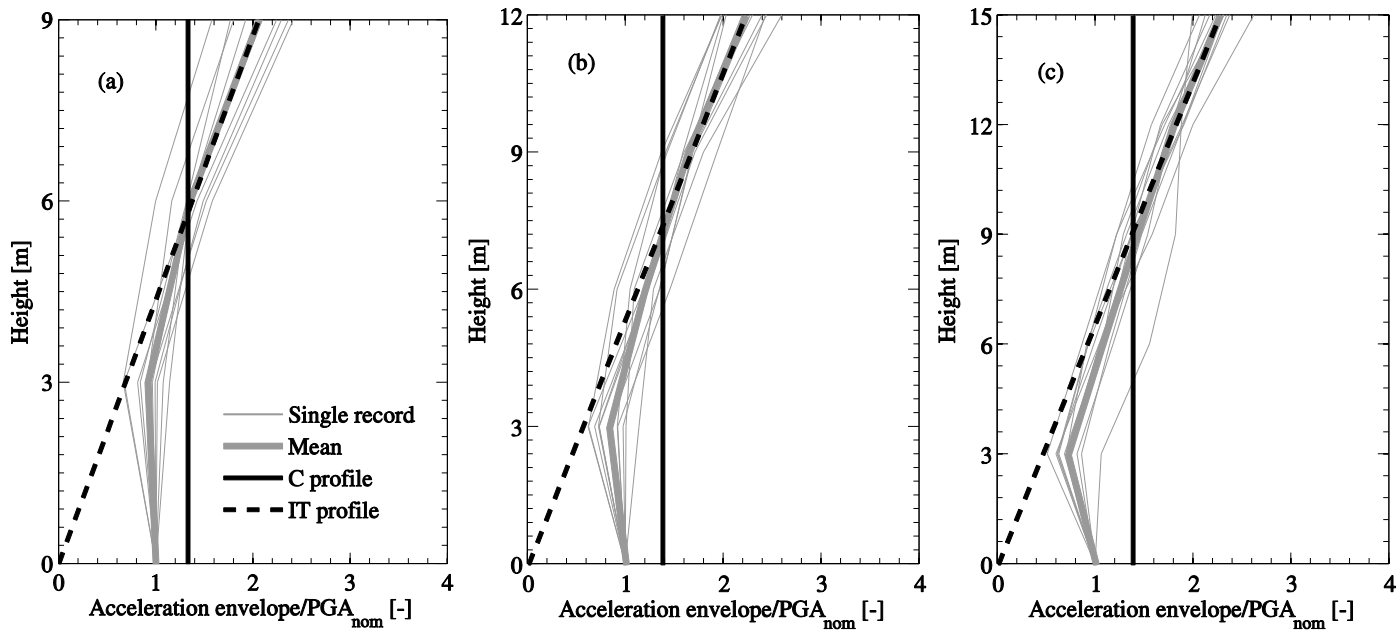

Fig. 6 Acceleration profiles for three mixed buildings (L1S3, L2S4 and L1S5, see Section 7 for the description of the three structures) and comparison with the constant (C) and inverted triangular (IT) acceleration profiles
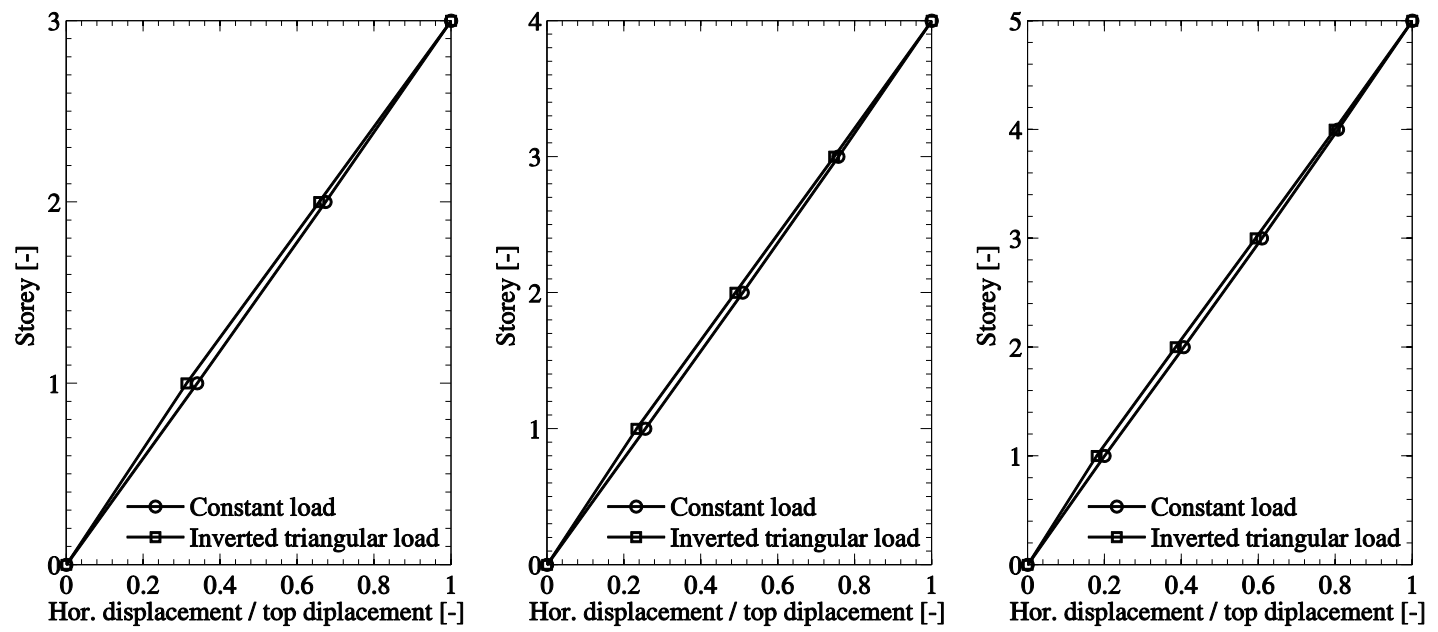

Fig. 7 Normalised displacement profiles for three case studies (3, 4 and 5 storeys): comparison between the displacement profiles obtained with the constant and inverted triangular load patterns

As a consequence, there is a theoretical inconsistency between the adoption of the uniformly distributed load and the actual lateral forces obtained from dynamic analyses. In order to check if the inconsistency might strongly affect the results, pushover analyses of mixed buildings are carried out with TREMURI. The analyses are performed with an inverted triangular and a constant load distribution and the resulting displacement profiles are compared at an average drift of $0.4 \%$. The results show that the displacement profile of mixed RC-URM buildings is not strongly affected by the assumed horizontal load pattern (Fig. 7). As a consequence, from an engineering point of view, the adoption of a constant load pattern for the evaluation of the displacement profiles at SD limit state is acceptable. 


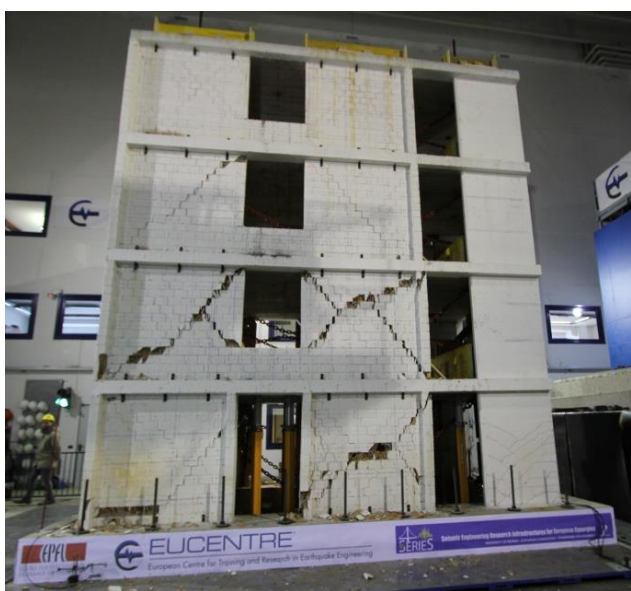

(a)

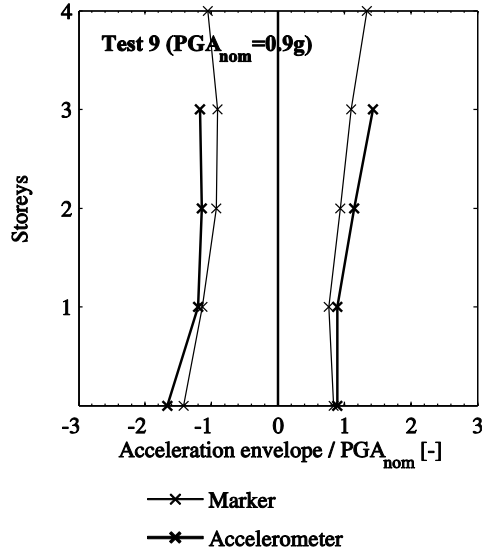

(b)

Fig. 8 Four-storey mixed RC-URM wall building (a). Normalised acceleration envelope for the last test (b), from Beyer et al. (2015)

Using a simple constant load pattern rather than a more complicated bilinear pattern is supported further by the following two findings reported in the literature:

(i) Shake table tests on a four-storey building composed of RC and URM walls (Beyer et al. 2015) have shown that, when the structure is close to failure, the acceleration profile is rather constant over the height (Fig. 8).

(ii) Mandirola (2014) simulated the test by Beyer et al. (2015) in TREMURI and compared the TREMURI acceleration profiles to those measured in the test. They observed that TREMURI tends to overestimate the acceleration amplification in the upper floors when the structure is close to failure.

\section{General direct displacement-based design procedure}

Direct displacement-based design is a procedure developed over the last 20 years (e.g., Priestley 1993, Priestley 1998, Priestley et al. 2007, Cardone et al. 2009, Pennucci et al. 2009, Pennucci et al. 2011, Sullivan et al. 2012) with the objective of mitigating weaknesses in the current force-based design approach. DDBD fundamentals are illustrated in Fig. 9: a multi-degreeof-freedom (MDOF) structure is converted into a single-degree-of-freedom (SDOF) system, Fig. 9(a). Given $m_{i}$ and $\Delta_{i}$ the floor masses and design displacements and $H_{i}$ the storey height, the design displacement $\Delta_{d}$, effective mass $m_{e}$ and effective height $h_{e}$ are calculated as

$$
\begin{gathered}
\Delta_{d}=\frac{\sum m_{i} \Delta_{i}^{2}}{\sum m_{i} \Delta_{i}} \\
m_{e}=\frac{\sum m_{i} \Delta_{i}}{\Delta_{d}}
\end{gathered}
$$




$$
h_{e}=\frac{\sum m_{i} \Delta_{i} H_{i}}{\sum m_{i} \Delta_{i}}
$$

In addition to $\Delta_{d}$, the bilinear envelope of the SDOF system is characterised by defining the yield displacement $\Delta_{y}$ from which the displacement ductility demand $\mu_{\Delta}$ is found, Fig. 9(b). $\mu_{\Delta}$ is then used to determine the equivalent viscous damping ratio $\xi_{e}$, representing the combined elastic damping and the hysteretic energy absorbed by the structure during inelastic deformations, Fig. 9(c). Once the equivalent viscous damping ratio $\xi_{e}$ is known, from the damping reduction factor $\eta_{\xi}$

$$
\eta_{\xi}=\left(\frac{0.07}{0.02+\xi_{e}}\right)^{0.5}
$$

the over-damped displacement spectrum is calculated and used to find the effective period of the structure, $T_{e}$, which corresponds to the period associated with the design displacement $\Delta_{d}$ (Fig. 9d). From $\mathrm{T}_{e}$ the effective stiffness of the structure and the design base shear force $V_{\text {base }}$ are derived

$$
\begin{gathered}
K_{e}=\frac{4 \pi^{2} m_{e}}{T_{e}^{2}} \\
V_{\text {base }}=K_{e} \Delta_{d}
\end{gathered}
$$

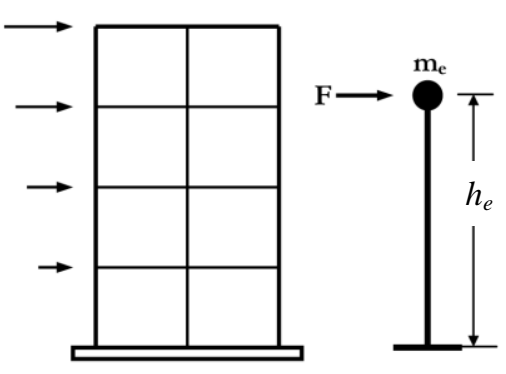

(a) SDOF Simulation

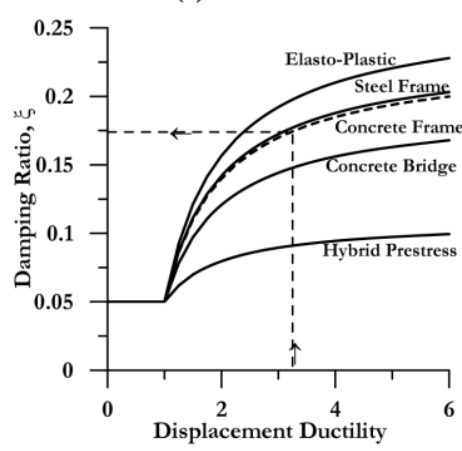

(c) Equivalent damping vs. ductility

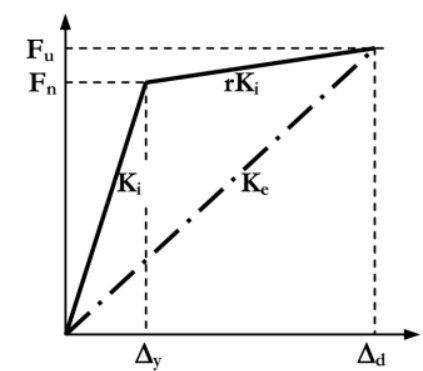

(b) Effective Stiffness $K_{\mathrm{e}}$

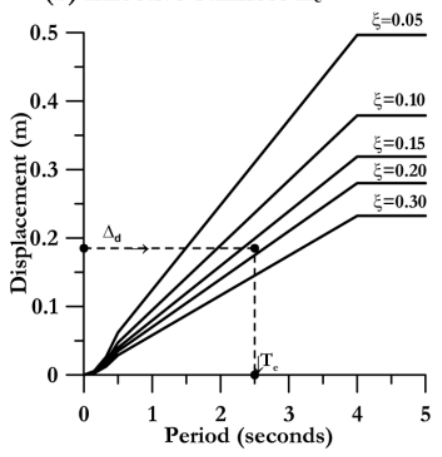

(d) Design Displacement Spectra

Fig. 9 Fundamentals of displacement-based design (Priestley 1998) 


\section{Evaluation of the equivalent viscous damping}

As presented in Section 4, DDBD requires the definition of an equivalent viscous damping $\xi_{e}$. Priestley et al. (2007) propose equations for calculating the equivalent viscous damping for different structural types and materials. For instance, for reinforced concrete walls the following equation is proposed

$$
\xi_{e}=0.05+0.444\left(\frac{\mu_{\Delta}-1}{\mu_{\Delta} \pi}\right)
$$

For URM walls, however, equations for the equivalent viscous damping $\xi_{e}$ are still preliminary (Sullivan et al. 2012). In particular, values of $\xi_{e}$ for the investigated URM walls (i.e., modern hollow clay brick masonry walls typically used in central Europe) were not found in literature. Therefore the objective of this section is to determine $\xi_{e}$ for the analysed typology of URM walls with dominant shear behaviour ( $\xi_{e}$ for URM walls with dominant flexural behaviour is not evaluated as the analysed URM walls are expected to exhibit a dominant shear behaviour). In the following, Section 5.1 outlines remarks related to the use of the equivalent viscous damping in DDBD and Section 5.2 describes how the equivalent viscous damping values for the studied URM walls $\left(\xi_{U R M}\right)$ have been calculated.

\subsection{Remarks with regard to the use of the equivalent viscous damping approach in DDBD}

As previously discussed, in DDBD (Priestley et al. 2007) the over-damped displacement spectrum is derived by multiplying the spectrum for 5\% damping with the damping reduction factor $\eta_{\xi}$ (Eq. (15)), which is a function of the equivalent viscous damping $\xi_{e}$. Recently, Pennucci et al. (2011) argued that expressions for the equivalent viscous damping $\xi_{e}$ are sensitive to the characteristics of the accelerograms (in particular, the elastic response spectra sensitivity to damping) used to calibrate the expressions and subsequently proposed an alternative method based on the displacement reduction factor $\eta_{i n}$, defined as the ratio of the maximum inelastic displacement to the elastic displacement at the effective period. This method does not require the definition of an equivalent viscous damping and is not significantly affected by ground motions characteristics.

In addition, Pennucci et al. (2011) observed that the $\xi_{e}$ is sensitive to the relative position of the spectral displacements at initial $\left(T_{i}\right)$ and effective $\left(T_{e}\right)$ periods with respect to $T_{C}$ and $T_{D}$. This effect, which might be particularly large for short period structures like mixed RC-URM buildings, might also explain the period dependency of the $\xi_{e}$ for short period structures (Priestley et al. 2007). To overcome this problem, Pennucci et al. (2011) suggest relating the inelastic demand to the demand slope factor $\rho$, which is a function of the relative position of initial and effective periods.

However, the demand slope factor approach is not yet implemented in the DDBD procedure and Pennucci et al. (2011) note the need for further research before it can be readily incorporated. As a consequence, this research builds on the equivalent viscous damping approach for evaluating the effective period of the structure. In order to account for the period dependency of $\xi_{e}$, a correction factor (Priestley et al. 2007) is applied. Note that Graziotti (2013) propose displacement reduction factors $\eta_{\text {in }}$ for solid clay brick masonry walls accounting for the likely failure mechanism. However, as the period dependency is not taken into account, these results are not used herein. 


\subsection{Evaluation of the equivalent viscous damping}

To evaluate the inelastic response of the URM walls studied herein, time history analyses on inelastic SDOF systems have been carried out. The ground motion set used in this study is composed of 12 non-stationary accelerograms (see also Michel et al. 2014) compatible with soil class $\mathrm{C}\left(T_{C}=0.6 \mathrm{~s}\right)$. The displacement spectra of these records have corner periods $T_{D}$ of about $2 \mathrm{~s}$ and all records are scaled to peak ground accelerations (PGA) of $2.5 \mathrm{~m} / \mathrm{s}^{2}$, (Fig. 10).

The equivalent viscous damping $\xi_{U R M}$ for URM walls failing in shear is determined in two steps: first, the damping $\xi_{U R M}$ is evaluated for structures with an initial period $T_{i}$ longer than $0.6 \mathrm{~s}$ and effective period $T_{e}$ shorter than $2 \mathrm{~s}$. For these systems the damping $\xi_{U R M}$ is assumed to be independent of $T_{e}$. Most URM and mixed URM-RC buildings will be, however, rather stiff and have initial periods shorter than $0.6 \mathrm{~s}$. In this period range the displacement spectrum does not vary linearly with $T$ but depends on $T^{3}$ or $T^{2}$. The influence of the spectral shape on the damping $\xi_{U R M}$ is accounted for in a second step, where URM walls with $T_{i}>0.1 \mathrm{~s}$ and $T_{e}<2 \mathrm{~s}$ are investigated.

As a first step, in order to avoid the influence of the spectral shape on the evaluation of $\xi_{U R M}$ and since the mean displacement spectrum is almost linear for $T_{C}=0.6 \mathrm{~s}<T<2 \mathrm{~s}=T_{D}$ (Fig. 10), SDOF systems with the following properties are investigated:

- The minimum considered initial period $\left(T_{i}\right)$ is equal to $0.6 \mathrm{~s}$;

- The maximum considered effective period $\left(T_{e}\right)$ is equal to $2 \mathrm{~s}$;

- The inelastic SDOF systems are modelled with the macro-element developed by Penna et al. (2013) and the dynamic analyses are carried out with TREMURI (Lagomarsino et al. 2013).

- Priestley et al. (2007) recommend performing the inelastic time-history analyses with 5\% tangent stiffness proportional damping. As tangent stiffness proportional damping is not available in TREMURI, all analyses are carried out with initial stiffness proportional viscous damping. For this case Priestley et al. (2007) propose to adopt an artificially low damping coefficient $\xi^{*}$

$$
\xi^{*}=5 \% \frac{1-0.1(\mu-1)(1-r)}{\sqrt{\frac{\mu}{(1+r \mu-r)}}}
$$

where $\mu$ is the ductility of the system and $\mathrm{r}$ is the post yield stiffness ratio, herein assumed equal to zero. Since the analysed SDOF systems exhibited ductilities between 2 and 6 (Fig. 11a), the artificially low damping coefficient $\xi^{*}$ obtained from the mean of these two ductilies corresponds to around $2 \%$, value which was used for all analyses.

The following procedure is adopted to find the equivalent viscous damping $\xi_{U R M}$ that should be used for the DDBD of URM wall structures failing in shear:

(i) An inelastic SDOF system representing a URM wall failing in shear is subjected to a selected ground motion.

(ii) The maximum displacement, the base shear at maximum displacement and the maximum ductility of the SDOF system are recorded. The effective period $T_{e}$ is therefore calculated as $T_{e}=2 \pi \sqrt{m_{e} / K_{e}}$. The effective stiffness $K_{e}$ is computed from the maximum displacement and the base shear at maximum displacement recorded in step (i); the effective mass is the mass of the SDOF system.

(iii) The equivalent viscous damping $\xi_{U R M}$ is calculated as the damping value that yields, for an elastic SDOF system with period $T_{e}$, the same maximum displacement as the inelastic SDOF system. 

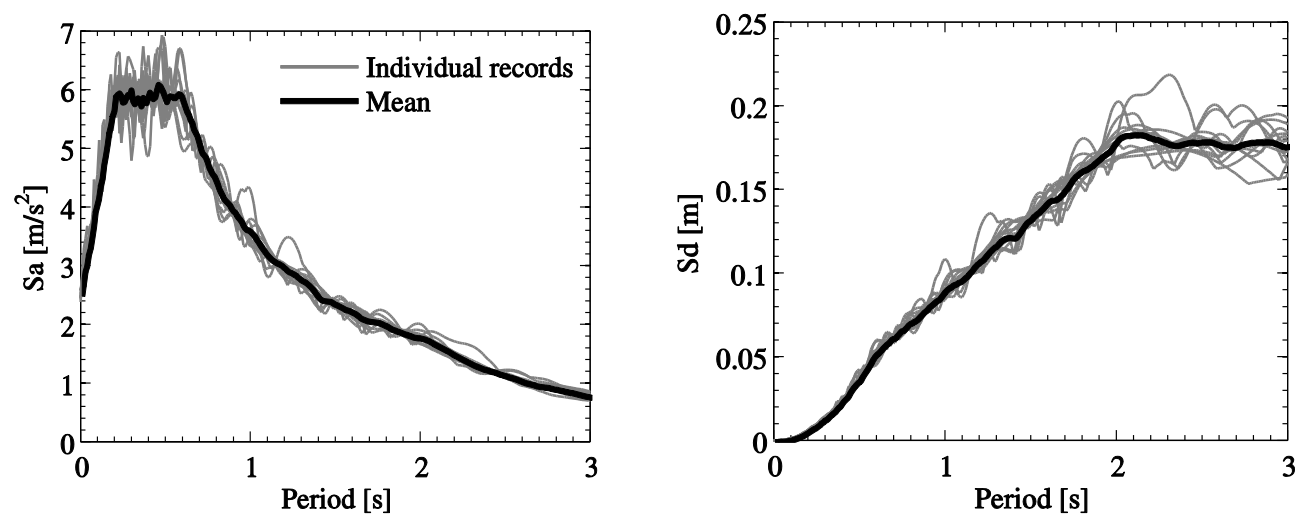

Fig. 10 Acceleration and displacement response spectra $(\xi=5 \%)$
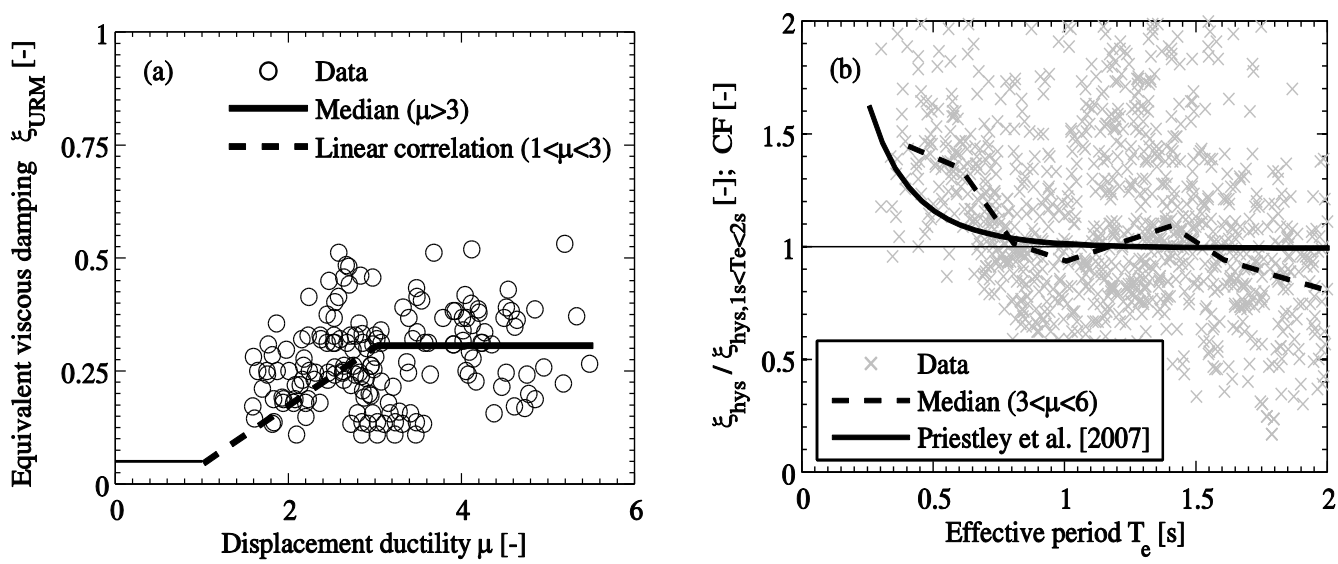

Fig. 11 (a): Displacement ductility versus $\xi_{U R M}$ for the inelastic SDOF systems with $T_{i}>0.6 \mathrm{~s}$ and $T_{\text {eff }}<2$ s. Data, linear relation for $1<\mu<3$ and median value for $\mu>3$. (b): Correction factor $C F$ to account for the period dependency of the hysteretic component of $\xi_{e}$ from Priestley et al. (2007) and data obtained from the second set of time history analyses

Fig. 11(a) shows that the equivalent viscous damping $\xi_{U R M}$ increases with displacement ductility $\mu$. In addition, for values of $\mu$ larger than $3, \xi_{U R M}$ is rather constant and its median value is $31 \%$. Since in the buildings analysed in this article the URM walls displayed always a displacement ductility higher than 3 and exhibited a dominant shear behaviour, $\xi_{U R M}$ is assumed equal to $31 \%$. For systems that remain elastic the damping is $5 \%$ and between $\mu=1$ and $\mu=3$ a linear increase in damping from 5\% to $31 \%$ can be assumed (Fig. 11a).

Since mixed RC-URM buildings are generally rather stiff structures, it is likely that their initial period is lower than $0.6 \mathrm{~s}$. In order to check the period dependency of $\xi_{U R M}$, a second set of analyses has been carried out. The new set comprised SDOF systems with initial periods $\left(T_{i}\right)$ longer than $0.1 \mathrm{~s}$, effective periods $\left(T_{e}\right)$ shorter than $2 \mathrm{~s}$ and displacement ductilities between 3 and 6 (the minimum ductility is set equal to 3 to avoid the ductility dependency of $\xi_{U R M}$ ).

The results of the analyses are plotted in Fig. $11 \mathrm{~b}$, where the hysteretic component of $\xi_{U R M}$ is normalised to its mean value obtained for $T_{e}$ between $1 \mathrm{~s}$ and $2 \mathrm{~s}$ (for $1 \mathrm{~s}<T_{e}<2 \mathrm{~s} \xi_{U R M}$ is assumed 
to be independent of $T_{e}$ ) and plotted versus the effective period $T_{e}$. The results show that $\xi_{U R M}$ is rather constant for $T_{e}$ between $1 \mathrm{~s}$ and $2 \mathrm{~s}$ and increases for $T_{e}$ smaller than $1 \mathrm{~s}$ (Fig. 11b, dashed line). In fact, for systems with $T_{e}<1 \mathrm{~s}$ and $\mu>3$, the initial periods are smaller than $0.6 \mathrm{~s}$. For $T<0.6$ $\mathrm{s}$, the displacement spectrum increases parabolically rather than linearly, which is reflected in higher values of $\xi_{U R M}$.

To account for the period dependence of $\xi_{U R M}$, a period dependent correction factor $C F$ is applied on the hysteretic component of the equivalent viscous damping $\left(\xi_{h y s}\right)$. The hysteretic model of the TREMURI macro-element failing in shear is the Takeda Thin (TT) rule and therefore the period dependency of the TT model proposed by Priestley et al. (2007) is adopted

$$
\xi_{h y s}=a\left(1-\frac{1}{\mu^{b}}\right)\left(1+\frac{1}{\left(T_{e}+c\right)^{d}}\right)
$$

where $a, b, c$ and $d$ are equal to $0.215,0.642,0.824$ and 6.444 (Priestley et al. 2007). The correction factor $C F$ is calculated as the ratio between $\xi_{\text {hys }}$ and $\xi_{\text {hys }}$ estimated at $T_{e}=4 \mathrm{~s}\left(\xi_{\text {hys } 4 s}\right)$

$$
C F=\frac{\xi_{\text {hys }}}{\xi_{\text {hys,4s }}}
$$

$C F$ is represented in Fig. 11(b) by the solid black line. Note that accounting for the effect of the spectral shape through a period dependent correction factor is rather crude and seems to underestimate the period dependency of $\xi_{U R M}$ for effective periods smaller than $0.8 \mathrm{~s}$. Once more advanced approaches are available, they can be used instead.

\section{Proposed methodology for mixed RC-URM wall structures}

The various steps of the displacement-based design methodology developed for structures with both RC and URM walls are presented in this section. To calculate the yield displacement of the $\mathrm{RC}$ walls, the technique follows the DDBD approach for designing regular RC frame-wall buildings (Sullivan et al. 2005, Sullivan et al. 2006), as the structural behaviour of both mixed systems is similar (Section 2). For mixed RC-URM wall structures the conversion of the MDOF system to the SDOF (Eqs. (12) to (17)) assumes a linear displacement profile over the height of the structure. This hypothesis will be checked at the end of the design. In the following, the DDBD process is broken down into a step-by-step procedure and summarised in the flowchart of Fig. 14

Step 1 - Preliminary design check of the plain URM wall building according to the DDBD approach

The procedure starts with the DDBD check of a plain URM wall edifice both for the design of new buildings and the retrofit of existing URM buildings. The objective is to verify that the masonry walls display a dominant shear behaviour and that the structure does not satisfy the seismic design check (Priestley et al. 2007). If it is the case, replacing one or more URM walls by $\mathrm{RC}$ ones is a promising strategy to develop a design or retrofit solution that can sustain the seismic demand.

Step 2 - Replacement of URM walls by RC walls and estimation of the overturning demand $\left(O T M_{\text {dem }}\right)$ and the effective period $\left(T_{e}\right)$

The designer chooses the URM walls to be replaced by RC ones. Even if the choice is arbitrary, 
it is suggested to $(i)$ conceive the RC walls as external walls to avoid a significant variation of axial force in the URM walls due to the shear forces transmitted by the slabs and to (ii) select symmetric layouts to obtain the same response whether the structure is pushed towards one direction or another.

From the SDOF simulation (Eqs. (12) to (17)) the effective period $T_{e}$ and the base shear $V_{b}$ are calculated. Consequently, the overturning moment demand $\left(O T M_{d e m}\right)$ can be estimated as, Figs. 12(a) and 12(b)

$$
\text { OTM }_{\text {dem }}=V_{\text {base }} h_{e}
$$

The equivalent viscous damping of the mixed system is not known at this stage but is assumed as $20 \%$ (the design examples have shown that the equivalent viscous damping of these systems varies between 15 and 25\%). In Step 9 it will be recalculated considering the effective energy dissipated by the RC and URM walls.

Step 3 - Estimation of the moment capacity of the mixed structure $\left(O T M_{\text {cap }}\right)$

The overturning moment capacity of the structure $\left(O T M_{\text {cap }}\right)$ is the sum of the contributions from the RC and URM walls $\left(M_{R C}, M_{U R M}\right)$ and the RC slabs $\left(M_{S}\right)$

$$
O T M_{\text {cap }}=M_{R C}+M_{U R M}+M_{S}
$$

The three contributions are represented in Figs. 12(c) and 12(d). In steps 4 and 5, $M_{U R M}$ and $M_{S}$ will be computed while $M_{R C}$ is yet unknown and is calculated as the required strength of the RC walls $\left(M_{R C, \text { req }}\right)$.

Step 4 - Contribution to the overturning capacity of the URM walls $\left(M_{U R M}\right)$

As the URM walls are expected to fail in shear, their moment capacity is estimated as a function of their shear strength $\left(V_{s h}\right)$. For a single wall $m, M_{U R M, m}$ results as

$$
M_{U R M, m}=V_{s h, m} H_{C F, U R M, m}
$$

$V_{s h, m}$ is the shear strength of the URM wall $m$ and can be estimated, for instance, according to Mann and Müller (1982), if material tests are available. If not, Eq. (10b) can be used for estimating the shear strength of the wall. $H_{C F, U R M, m}$ is the height of the contra-flexure point of the URM wall. Its lower bound value corresponds to half of the storey height $\left(h_{s t}\right)$. Two empirical parameters are added for the calculation of $H_{C F, U R M}$. The first one, $\gamma$, accounts for the fact that $H_{C F, U R M}$ increases with the number of storeys $(n)$

$$
\gamma=1+n / 10
$$

The second parameter, $\psi$, takes into account the aspect ratio of the single URM wall. If $h_{s t}>l_{U R M},\left(l_{U R M}\right.$ is the length of the URM wall), $H_{C F, U R M}$ increases proportionally to $\psi$, otherwise it is equal to 1

$$
\begin{array}{cc}
\text { If } h_{s t}>l_{\mathrm{URM}} & \psi=h_{s t} / l_{\mathrm{URM}} \\
\text { If } h_{s t} \leq l_{\mathrm{URM}} & \psi=1
\end{array}
$$

The total contribution of the URM walls to the overturning capacity $\left(M_{U R M}\right)$ is the sum of the base moments of the individual URM walls $\left(M_{U R M, m}\right)$ 


$$
\begin{gathered}
M_{U R M}=\sum_{m} M_{U R M, m} \\
M_{U R M, m}=V_{s h} H_{C F, U R M}=V_{s h}\left(\frac{h_{s t}}{2} \gamma \psi\right)
\end{gathered}
$$

\section{Step 5 -Contribution of the $R C$ slabs to the overturning capacity $\left(M_{S}\right)$}

The contribution of the RC slabs to the overturning capacity $\left(M_{S}\right)$ is estimated by following the procedure developed for irregular RC frames (Priestley et al. 2007), in which the contribution of each bay is accounted for separately. In the following, the technique for calculating $M_{S}$ is broken down into five sub-steps:

Step 5a: The overturning moment resisted by the slabs is calculated by separating the contributions of the different bays $\left(M_{b a y, j}\right)$. Given $j$ the number of bays, $M_{S}$ results as follows

$$
M_{S}=\sum_{j} M_{b a y, j}
$$

Step 5b: Each $M_{b a y, j}$ is calculated as the sum of the shear forces transmitted by the RC slabs $\left(\Sigma V_{j i}\right)$ of the considered bay $j$, multiplied by its length $\left(L_{b a y, j}\right)$, Figs. 12(c) and 12(d). Given $i$ the number of storeys $M_{b a y, j}$ results as

$$
M_{b a y, j}=\left(\sum_{i} V_{j i}\right) L_{b a y, j}
$$

Step 5c: Unlike capacity designed RC frames, in URM and mixed RC-URM buildings the connections between URM walls and RC slabs form in general a weak column-strong beam mechanism. This implies that the RC slabs remain largely elastic and the shear forces transmitted by the slabs cannot be estimated from their moment capacity.

Back-analysis of tests has shown that in URM and mixed RC-URM buildings, in order to correctly estimate the shear forces transmitted by the slabs $\left(\Sigma V_{j i}\right)$, the uplift of the RC slabs from the URM walls needs to be captured by the model. To calculate $\Sigma V_{j i}$, the RC slabs of each storey are then represented by "elastic continuous beams" which are mono dimensional elements characterised by their length only. The elastic continuous beams are sustained by vertical supports representing the URM walls. The supports work only in compression to take into account the possible uplift of the slabs from the masonry walls, Fig. 13(b). The connections between the elastic continuous beams and the RC walls are represented by pins through which the moment transmitted to the RC walls $\left(M_{s, w}\right)$ is applied. The pins can, instead, also transmit tension forces.

Step 5d: As input, the geometry of the walls is required. Since at the beginning of the design the dimensions of the RC walls are unknown, a trial length, which will be adjusted during the design procedure, has to be assumed. For the construction of the elastic continuous beam models, four additional aspects have to be examined:

(i) Position and number of the supports (for each masonry wall): The supports represent the position of the resulting forces where the slabs transmit the forces to the URM walls below. For squat URM walls, i.e., when $l_{U R M} / h_{s t}>1$, two supports, as shown in Figs. 13(a) and 13(b), are introduced. For slender walls $\left(l_{U R M} / h_{s t}<1\right)$, just one support is required, Figs. 13(a) and 13(b).

(ii) Position of the tributary weight of the slabs $\left(W_{s}\right)$ : The tributary weight of the slabs $W_{s}$ is 
modelled as a concentrated force applied at the centreline of each URM wall, Fig. 13(b).

(iii) Magnitude and position of the forces representing the weight transmitted by the walls above the considered storey $\left(W_{u p}\right)$ : For each wall, the weights transmitted by the walls above the considered storey $\left(W_{u p}\right)$ are $(i)$ calculated as the sum of the tributary reaction forces of the above slab (Fig. 13b, dotted lines) and (ii) applied as shown in Fig. 13(b).

(iv) Bending moment applied to the pins connecting the slabs to the $R C$ walls $\left(M_{s, w}\right)$ : Firstly, the yield rotation $\left(\theta_{y s}\right)$ and the rotation demand $\left(\theta_{s}\right)$ of the slabs are calculated. The former can be computed according to Priestley et al. (2007)

(a)

URM wall 1

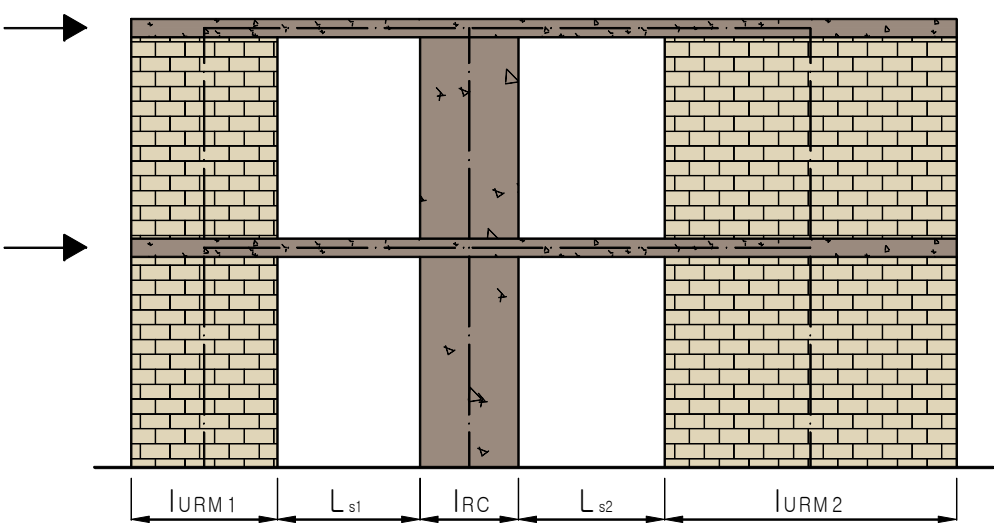

(c)

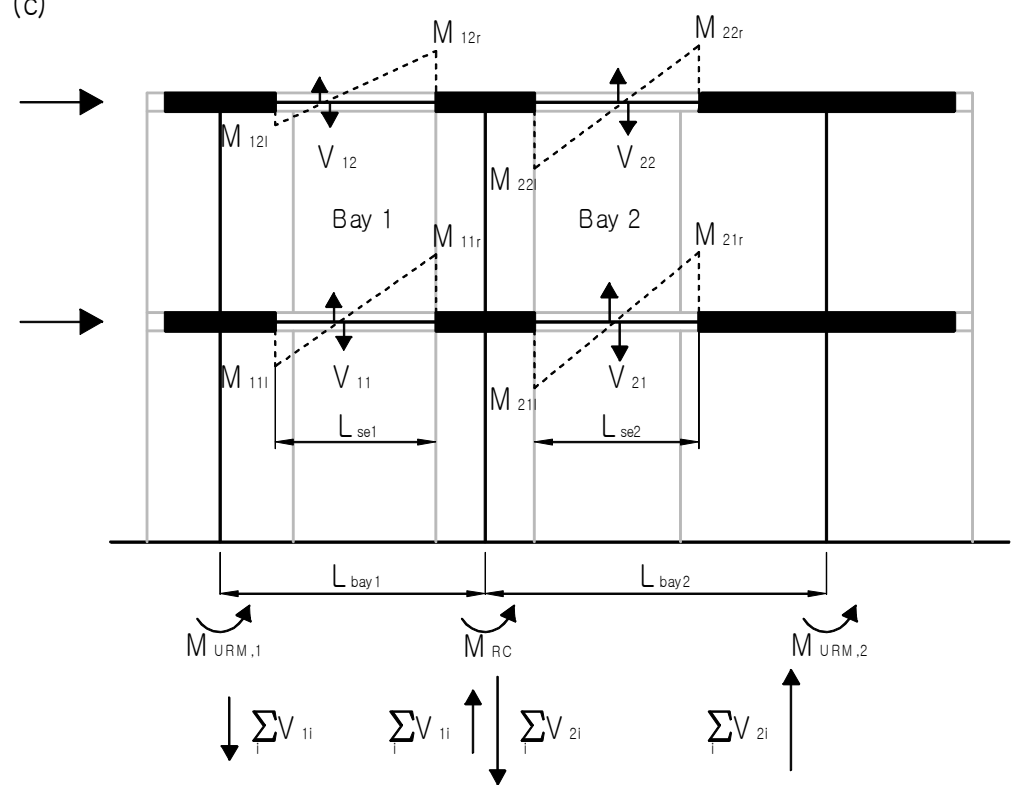

(b)

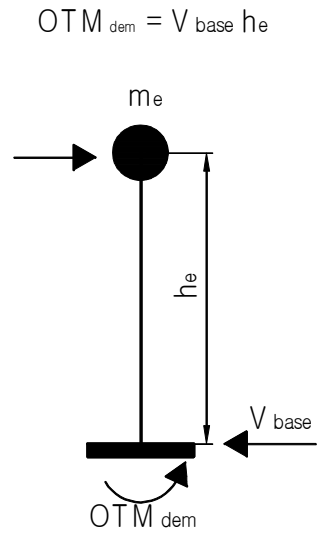

(d)

$$
\begin{aligned}
& \mathrm{OTM}_{\text {cap }}=M_{\mathrm{RC}}+\mathrm{M}_{\mathrm{URM}}+\mathrm{M}_{\mathrm{s}} \\
& \mathrm{M}_{\mathrm{RC}}=\sum \mathrm{M}_{\mathrm{RC}, \mathrm{r}} \\
& \mathrm{M}_{\text {URM }}=\sum_{\mathrm{m}} \mathrm{M}_{\text {URM, } \mathrm{m}} \\
& \mathrm{M}_{\mathrm{s}}=\sum \mathrm{M}_{\text {bay } \mathrm{j}} \\
& M_{\text {bay } 1}=\left(\sum V_{1 i}\right) L_{\text {bay } 1} \\
& M_{\text {bay, } 2}=\left(\sum V_{2 i}\right) L_{\text {bay2 }} \\
& \text { With: } \\
& r=\text { number of } R C \text { walls } \\
& m=\text { number of URM walls } \\
& \mathrm{j}=\text { number of bays } \\
& i=\text { number of storeys }
\end{aligned}
$$

Fig. 12 Seismic response of a RC-URM structure. SDOF simulation and estimation of the $\operatorname{OTM}_{d e m}(\mathrm{a}, \mathrm{b})$; seismic contribution of the different structural systems and evaluation of the $O T M_{c a p}(\mathrm{c}, \mathrm{d})$ 


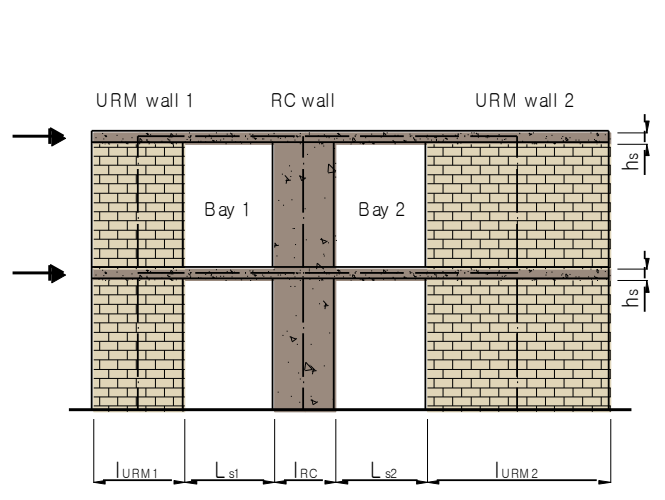

(a)

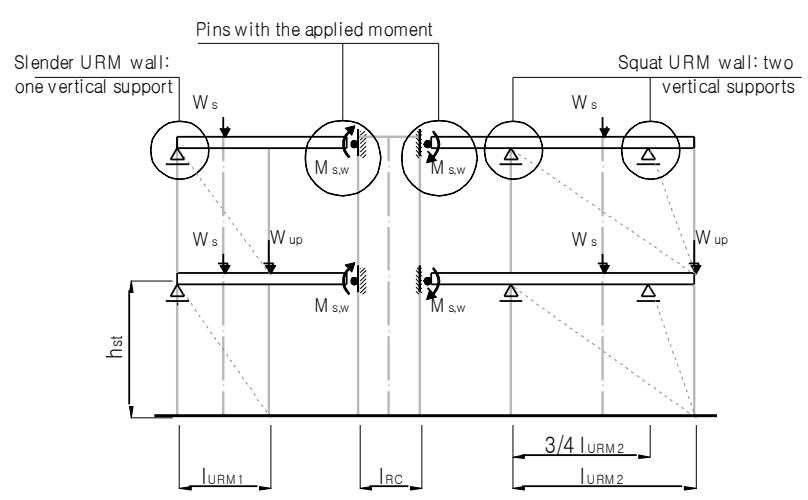

$\underline{\Xi}=$ Vertical supports $\quad$ 胗=Pins

(b)

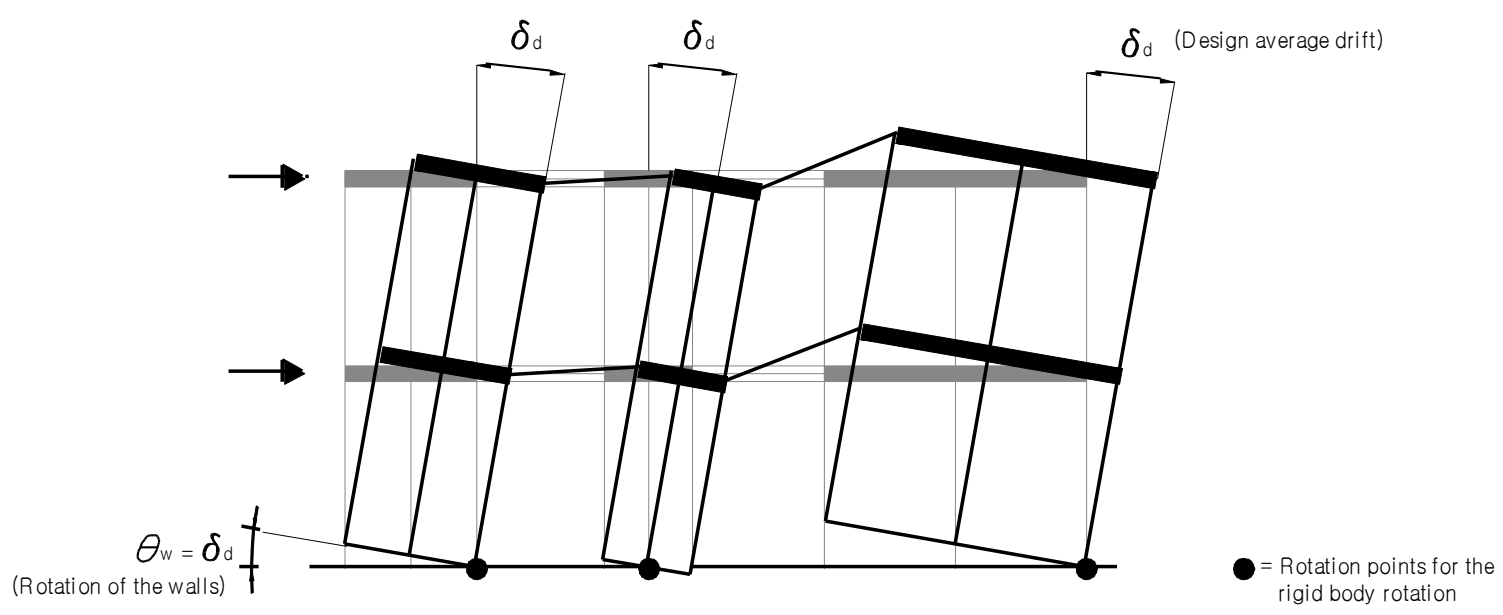

(c)

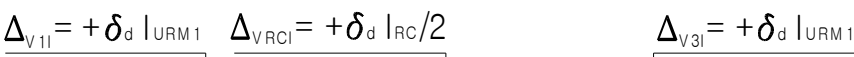

Rotation demand RC slabs of bay 1 :

$$
\theta_{\mathrm{s} 1}=\frac{\Delta_{\mathrm{V} 1 \mathrm{r}}+\Delta_{\mathrm{VRCl}}}{\mathrm{L}_{\text {sel }}} \quad \mathrm{L}_{\mathrm{se} 1}=\mathrm{L}_{\mathrm{s} 1}+\mathrm{h}_{\mathrm{s}}
$$

$$
\theta_{\mathrm{s} 2}=\frac{-\Delta_{\mathrm{VRCr}}+\Delta_{\mathrm{V} 31}}{\mathrm{~L}_{\mathrm{se} 2}} \quad \mathrm{~L}_{\mathrm{se} 2}=\mathrm{L}_{\mathrm{s} 2}+\mathrm{h}_{\mathrm{s}}
$$$$
\text { Rotation demand RC slabs of bay } 2 \text { : }
$$

Fig. 13 Mixed RC-URM wall structure (a). Construction of the elastic continuous beams (b). Walls and RC beams mechanisms for calculating the rotation demand $\theta_{b 1}$ and $\theta_{b 2}(\mathrm{c}, \mathrm{d})$ 


$$
\theta_{y s}=0.35 \varepsilon_{y} \frac{L_{s e}}{h_{s}}
$$

The deformable part of the RC slabs $\left(L_{s e}\right)$ is the free span of the slab $\left(L_{s}\right)$ increased by its section depth $\left(h_{s}\right)$ on either side where it frames into URM walls (Priestley et al. 2007, Paparo and Beyer 2015). From geometrical considerations, the rotation demand $\theta_{s}$ on the slab is related to the design drift $\delta_{d}$. To simplify matters, the rotation demand is estimated assuming that URM and RC walls undergo only rigid body deformations. For the URM walls a rigid body rotation around the base corner in compression is assumed; for the $\mathrm{RC}$ walls a rigid body rotation around its centreline, Figs. 13(c) and 13(d). As rigid body rotations are assumed, the rotation of the walls $\left(\theta_{w}\right)$ is equal to the design average drift $\left(\delta_{d}\right)$. More advanced kinematic models are of course feasible but might not be necessary at this stage of the design. The flexural moment capacity of the slab $\left(M_{y s, w}\right)$ can be calculated by considering an effective slab width equal to three times the wall thickness [Priestley et al.2007], allowing to compute the bending moment $M_{s, w}$ as

$$
\begin{array}{cc}
\text { If } \theta_{s}>\theta_{y s} & M_{s, w}=M_{y s, w} \\
\text { If } \theta_{s}<\theta_{y s} & M_{s, w}=\frac{\theta_{s}}{\theta_{y s}} M_{y s, w}
\end{array}
$$

Step 5e: The procedure to determine the shear transmitted by the RC slabs starts from the top storey and progresses downwards floor by floor. At the top floor the force $W_{u p}$ is equal to zero, $W_{s}$ and $M_{s, w}$ are known and the reaction forces of the supports can be calculated. By summing up the tributary reaction forces from the slabs above (Fig. 13b, dotted lines), the forces $W_{u p}$ applied to the walls of the storey below are determined. The procedure continues down to the first floor.

Step 6 - Choice of the ductility of the RC walls $\left(\mu_{1 R C}\right)$

The designer chooses the level of ductility which the RC walls will undergo. The quasi-static and dynamic tests on mixed RC-URM wall structures (Paparo and Beyer 2014, Beyer et al. 2014, Tondelli et al. 2014) have shown that the RC walls experience very small inelastic deformations when the URM walls failed. Hence, regarding the design at the SD limit state, it is pertinent to choose that the RC walls will exhibit a displacement ductility $\mu_{\triangle R C}$ within the range of 1 and 2 .

Step 7 - Calculation of the height of the contra-flexure point of the $R C$ walls $\left(H_{C F, R C}\right)$

From Eq. (5b) the height of the contra-flexure point of the RC walls $H_{C F, R C}$ is estimated by setting $M_{2}(x)$ equal to zero and solving for $x$. The parameter $\beta_{R C}$ is calculated as the ratio $M_{R C}$ over OTM dem $_{\text {. }}$

Step 8 - Calculation of the length of the $R C$ walls $\left(l_{R C}\right)$

From Step 6 the target yield displacement of the RC walls at the effective height is known $\left(\Delta_{y R C}=\Delta_{d} / \mu_{\triangle R C}\right)$. With Eqs. (32a) and (32b) the yield curvature of the RC walls $\left(\varphi_{y R C}\right)$ can be estimated (Sullivan et al. 2005)

$$
\begin{gathered}
\text { For } h_{e}<H_{C F, R C} \quad \phi_{y R C}=\Delta_{y R C}\left(\frac{h_{e}^{2}}{2}-\frac{h_{e}^{3}}{6 H_{C F, R C}}\right)^{-1} \\
\text { For } h_{e}>H_{C F, R C} \\
\phi_{y R C}=\Delta_{y R C}\left(\frac{H_{C F, R C} h_{e}}{2}-\frac{H_{C F, R C}^{2}}{6}\right)^{-1}
\end{gathered}
$$


The equations are based on a linear moment profile up to $H_{C F, R C}$ and zero moment between $H_{C F, R C}$ and the top of the wall. From the yield curvature, the required wall length $l_{R C}$ can be found

$$
l_{R C}=\frac{2 \varepsilon_{y}}{\phi_{y R C}}
$$

Step 9 - Calculation of the equivalent viscous damping $\xi_{\text {sys }}$ and the damping reduction factor $\eta_{\xi}$

The equivalent viscous damping of the system $\xi_{s y s}$ is obtained from a weighted average proportional to the base shear carried by URM and RC walls

$$
\xi_{s y s}=\frac{V_{U R M} \xi_{U R M}+V_{R C} \xi_{R C}}{V_{\text {base }}}
$$

$\xi_{R C}$ is the damping associated with the RC walls and can be calculated according to Eq. (35), as the displacement ductility of the RC walls is known

$$
\xi_{R C}=0.05+0.444\left(\frac{\mu_{\Delta R C}-1}{\mu_{\triangle R C} \pi}\right)
$$

As pointed out in Section 5, the damping associated with the URM walls, $\xi_{U R M}$, can be assumed equal to $31 \%$. This value can be used only if the URM walls fail in shear and if they feature displacement ductilities larger than 3 . These requirements are generally fulfilled for the design of such structures for the SD limit state. The hysteretic components of the equivalent viscous damping $\xi_{s y s}$ is then corrected according to the correction factor $C F$ (Eq. (21), Section 5.2) in order to account for their period dependency. The damping reduction factor $\eta_{\xi}$, used to compute the spectrum for the desired $\xi_{s y s}$, is then calculated according to Eq. (15).

Step 10 - Re-evaluation of the overturning moment demand $\left(O T M_{\text {dem }}\right)$ and calculation of the required strength of the $R C$ walls $\left(M_{R C r e q}\right)$

The new effective period $T_{e}$ is found by entering the reduced displacement spectrum with the design displacement $\Delta_{d}$. The effective stiffness $K_{e}$ and the base shear $V_{b a s e}$ are consequently determined according to Eqs. (16) to (17). The overturning moment demand OTM dem, approximated in step 2 by assuming an equivalent viscous damping of $20 \%$, is now re-calculated by multiplying the base shear $V_{\text {base }}$ to the effective height he (Eq. (22)). The required moment capacity of the RC walls $\left(M_{R C r e q}\right)$ is then obtained as

$$
M_{R C r e q}=O T M_{d e m}-M_{S}-M_{U R M}
$$

Step 11 - Iterations to find a stable solution

Steps 3 to 10 are iterated until a stable solution is found. The change in required strength of the $\mathrm{RC}$ walls $\left(M_{R C r e q}\right)$ is used as convergence criterion. It is suggested that, if the strength varies less than $5 \%$ from one step to the other, the solution can be considered as stable.

Step 12 - Ascertain the displacement profile of the structure

The DDBD procedure assumes a linear displacement profile over the height of the structure. To check this hypothesis, Eq. (11) is used. It is postulated that the profile can be considered as linear if $R_{\delta}$ is between 0.80 and 1.25 (Section 3.3). If this requirement is not fulfilled, the designer has two options: (i) to choose a different number of URM walls to be replaced by RC ones and recheck the procedure from Step 2 or $(i i)$ to change the level of displacement ductility $\left(\mu_{\triangle R C}\right)$ of the $\mathrm{RC}$ walls (Step 6). 


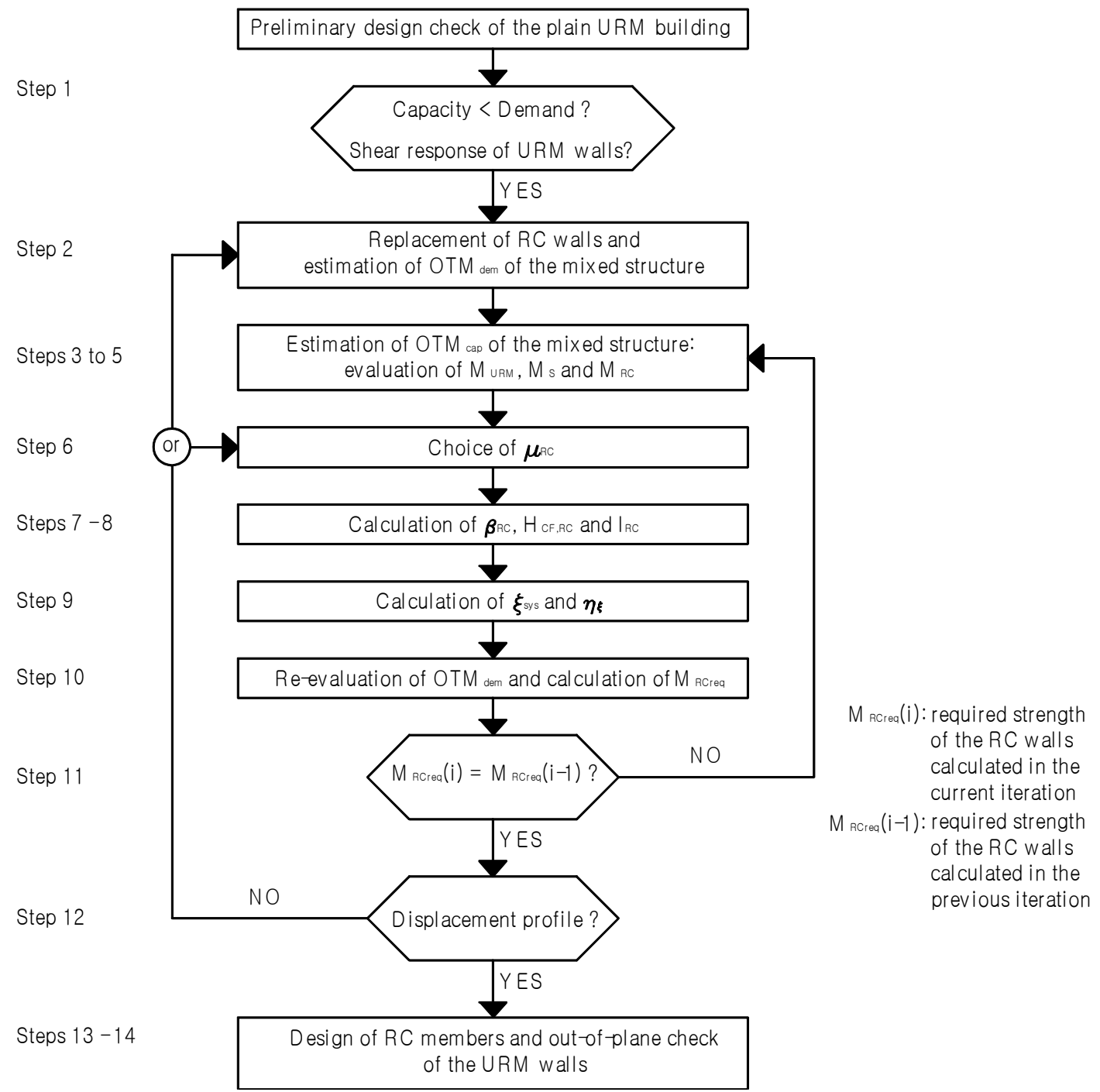

Fig. 9 Flowchart of the DBD methodology for RC-URM wall structures

\section{Step 13 - Design of RC members}

Due to the low displacement ductility that the RC members will be subjected to, spalling of the cover concrete is often unlikely and detailing requirements for the confinement reinforcement can be relaxed. The design procedure does not check the displacement capacity of the RC members as, in the herein examined typology of mixed buildings, the RC members are always designed to develop a flexure mechanism with displacement capacities exceeding those of URM walls. In fact, the RC walls need to reach only displacement ductilities of $\mu_{\triangle R C}=1-2$, values which can be easily reached by RC walls (e.g., Hannewald 2013). Additionally, experimental evidence (Paparo and Beyer 2014, Beyer et al. 2014) has clearly shown that the URM walls are the critical elements in this typology of mixed structures.

In the vicinity of the URM walls, the RC slabs do in general not yield because they uplift from 
the URM walls. The slabs might yield where they frame into the RC walls. However, the rotation ductility demand generally does not exceeds 2.5 , also for the slabs with short spans. Additionally, very short spans (say, less than $0.75 \mathrm{~m}$ ) are rather unlikely in modern residential buildings. Also the dynamic analyses presented in the following section demonstrate that the RC members are not critical and there is no need for their displacement capacity check.

\section{Step 14 - out-of-plane check of the URM walls}

The out-of-plane check of URM walls can be carried out in accordance with EN 1998-1 (2004) where the thickness and the slenderness of the masonry walls have to fulfil the following criteria

Low seismicity:

$$
\begin{gathered}
t_{e f} \geq 17 \mathrm{~cm} \\
h_{e f} / t_{e f} \leq 15[-] \\
t_{e f} \geq 24 \mathrm{~cm} \\
h_{e f} / t_{e f} \leq 12[-]
\end{gathered}
$$

High seismicity:

$t_{e f}$ and $h_{e f}$ are the effective thickness and height of the URM wall calculated according to EN1998-1 (2004).

\section{Case studies}

In order to verify the accuracy of the displacement-based design procedure in terms of meeting the assumed performance level, several mixed RC-URM wall structures are designed according to the proposed method (Section 7.1). The buildings are conceived for the design level earthquake to reach the SD limits state. The limit state is controlled by the URM walls to which a drift capacity equal to $0.4 \%$ is assigned (EN1998-3 2005). Assuming further a constant inter-storey drift over the height of the structure, the SD limit state is therefore reached if the average drift corresponds to $0.4 \%$.

Based on the DDBD outputs, two-dimensional non-linear models are set up and subjected to one set of ground motions which are compatible with the design spectrum (Section 7.2). The performances of the structures are then gauged comparing design quantities, such as displacement profiles and reaction forces at the base of the walls, to the results from the simulations (Section 7.3).

\subsection{Description of the case studies}

Several configurations of 3, 4 and 5 storey modern RC-URM wall structures are designed using the new methodology. At the beginning of the procedure, the DDBD check of plain URM wall structures is carried out to check that the masonry walls display a dominant shear behaviour and that the structure does not satisfy the seismic design requirement. The objective is to ascertain that replacing one or more URM walls by RC ones will increase not only the strength but also the displacement capacity of the mixed system in comparison to the plain URM buildings. Fig. 15 represents the elevation of the 4-storey buildings with the position of the RC walls replacing the masonry. The RC walls are drawn with dotted lines to stress that their length is not an input parameter. 
Concerning the geometry of the structures, the thickness of all walls in these case studies is always $0.30 \mathrm{~m}$. As two-dimensional simulations are carried out, $\mathrm{RC}$ beams with a cross section of $0.25 \times 0.90 \mathrm{~m}$ represent the slabs. Again, the width of the RC beams is set equal to three times that of the walls according to Priestley et al. (2007). The area of the longitudinal reinforcements of the $\mathrm{RC}$ beams is always equal to $1000 \mathrm{~mm}^{2}\left(\rho_{C B}=0.51 \%\right)$ and their free span is $1.00 \mathrm{~m}$. The axial stress ratios $\sigma_{0} / f_{m}$ at the base of the URM walls are around $5.3 \%, 7.1 \%$ and $8.8 \%$ for the 3,4 and 5 storey configurations. The transverse reinforcements of all RC members are designed to avoid shear failure and develop a stable flexural response with a larger deformation capacity than that of the URM walls. The structures are located in an area of moderate seismicity and the seismic demand is represented by an acceleration design spectrum of soil class $C\left(T_{B}=0.2 \mathrm{~s} ; T_{C}=0.6 \mathrm{~s}\right.$ and $T_{D}=2 \mathrm{~s}$ (EN 1998-1 2004)) with PGA equal to $0.25 \mathrm{~g}$ (Fig. 16). Table 4 summarises the main characteristics of the structures and the key DDBD outputs. Note that the increase of $\xi_{h y s}$ due to its period dependency (Priestley et al. 2007) ranged between 4\% (5 storeys structures) and 12\% (3 storeys structures).

\subsection{Modelling and analyses}

To assess the designs, the case studies are modelled and analysed through inelastic time history analyses (ITHA) using the TREMURI software (Penna et al. 2013, Largomarsino et al. 2013). The mechanical properties adopted are those presented in Section 3.2.2 (Table 3) except the equivalent
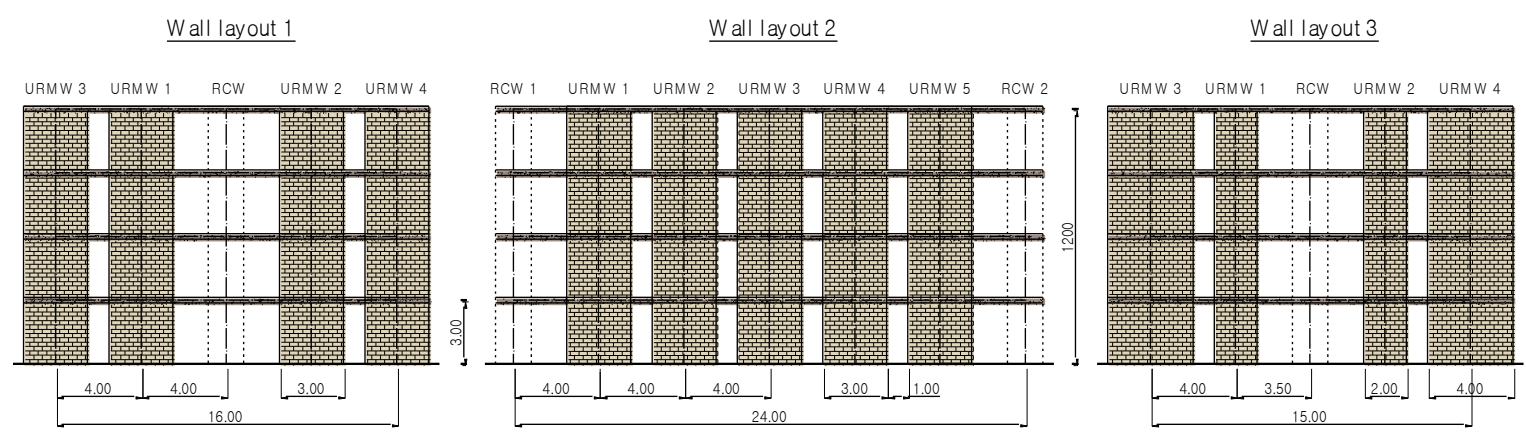

Fig. 15 Elevation of the 4 storey buildings. All dimensions in $\mathrm{m}$
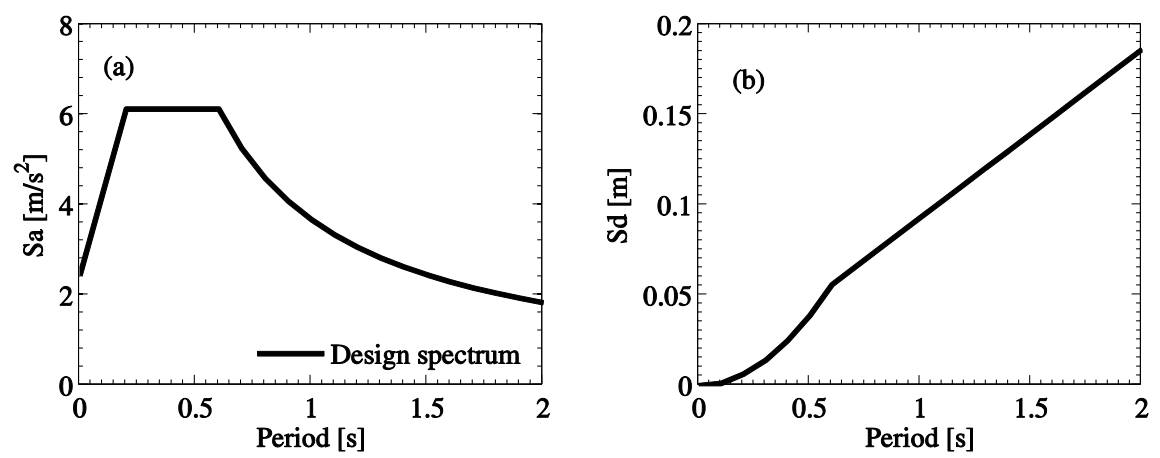

Fig. 16 Acceleration and displacement design spectra 
Table 4 Characteristics of the RC-URM wall structures and key design outputs from DBD approach

\begin{tabular}{|c|c|c|c|c|c|c|c|c|c|}
\hline \multirow{6}{*}{$\begin{array}{c}\text { Wall } \\
\text { layout } \\
1\end{array}$} & \multicolumn{3}{|c|}{$\begin{array}{c}\text { Characteristics of the mixed } \\
\text { structures }\end{array}$} & \multicolumn{6}{|c|}{$\begin{array}{c}\text { DDBD, } \\
\text { key outputs }\end{array}$} \\
\hline & \multirow{2}{*}{ Name } & $H$ & $M$ & $\mu_{\Delta R C}$ & $T_{1}$ & $T_{e}$ & $M_{R C}$ & $l_{R C}$ & $\rho_{\text {mean }}$ \\
\hline & & {$[\mathrm{m}]$} & {$[\mathrm{t}]$} & {$[-]$} & {$[\mathrm{s}]$} & [s] & [kNm] & {$[\mathrm{m}]$} & {$[\%]$} \\
\hline & L1S3 & 9 & 306 & 1.8 & 0.26 & 0.57 & 1720 & 2.81 & 0.20 \\
\hline & L1S4 & 12 & 408 & 1.6 & 0.34 & 0.69 & 2280 & 3.09 & 0.22 \\
\hline & L1S5 & 15 & 510 & 1.2 & 0.47 & 0.84 & 2250 & 2.66 & 0.28 \\
\hline Wall & L2S3 & 9 & 428 & 1.8 & 0.27 & 0.56 & 1530 & 2.60 & 0.21 \\
\hline layout & L2S4 & 12 & 571 & 1.6 & 0.37 & 0.67 & 1930 & 2.70 & 0.24 \\
\hline 2 & L2S5 & 15 & 714 & 1.2 & 0.50 & 0.82 & 1720 & 2.17 & 0.31 \\
\hline Wall & L3S3 & 9 & 306 & 1.8 & 0.25 & 0.57 & 1360 & 2.44 & 0.21 \\
\hline layout & L3S4 & 12 & 408 & 1.6 & 0.35 & 0.70 & 1410 & 2.33 & 0.22 \\
\hline 3 & L3S5 & 15 & 510 & 1.2 & 0.46 & 0.86 & 1400 & 2.15 & 0.24 \\
\hline
\end{tabular}

H: total height

M: total mass

$\mu_{\triangle R C}:$ design ductility of the $R C$ wall $(s)$

$T_{1}$ : first modal period

$T_{e}$ : effective period

$M_{R C}:$ design strength of the $R C$ wall $(s)$

$l_{R C}$ : length of the $R C$ wall $(s)$

$\rho_{\text {mean }}$ : mean longitudinal reinforcement ratio of the $R C$ wall(s)

*The name stands for "Layout X Storeys $X$ "

cohesion $c_{e q}$ since the axial stress ratios at the base of the URM walls $\left(\sigma_{0} / f_{m}\right)$ are different to the previous case studies (Section 3.2). $c_{e q}$ results equal to $0.063,0.084$ and $0.106 \mathrm{MPa}$ for the 3,4 and 5 storey configurations.

The structures are subjected to the set of accelerograms outlined in Section 5.2. In the spectra the position of the corner period $T_{D}$ (equal to $2 \mathrm{~s}$ ) does not influence the results since the structures do not exhibit periods larger than $2 \mathrm{~s}$ (see Table 4). The accelerograms are scaled to a PGA equal to $0.25 \mathrm{~g}$ to match the design displacement spectrum adopted in the design procedure (Fig. 16). Damping is modelled using initial stiffness proportional viscous damping ratio $\xi^{*}$. The value of $\xi^{*}$ is the lowered damping coefficient computed according to Priestley et al. (2007) (Eq. (19)) as tangent stiffness proportional damping is replaced with initial stiffness proportional damping since only the latter is available in TREMURI. The ductility of the system $\mu$ is approximated as $\left(T_{e} / T_{i}\right)^{2}$, see Table 4.

\subsection{Results of time-history analyses}

To validate the design method, this section compares the design assumptions to the responses obtained form ITHA for the design level earthquake (PGA=0.25 g). Figs. 17 and 18 present the maximum displacement profiles, their median and the target design values associated with $0.4 \%$ average drift. Review of the results indicates that the procedure has performed well in limiting concentration of deformations in one single storey and in providing a linear displacement profile. 
On the other hand, for the three storey configurations, the maximum displacements obtained from ITHA are rather smaller than the corresponding design value. This difference is most likely caused by the approximate manner in which the period dependency of $\xi_{U R M}$ has been accounted for. In fact, it seems that the correction factor $C F$ (Eq. (21), Section 5.2) underestimates the period dependency of $\xi_{U R M}$ for effective periods shorter than $0.8 \mathrm{~s}$ (Fig. 11b). For configurations with longer effective periods (i.e., the four and five storey structures), the difference between the maximum displacements obtained from ITHA and the design displacements decreases.
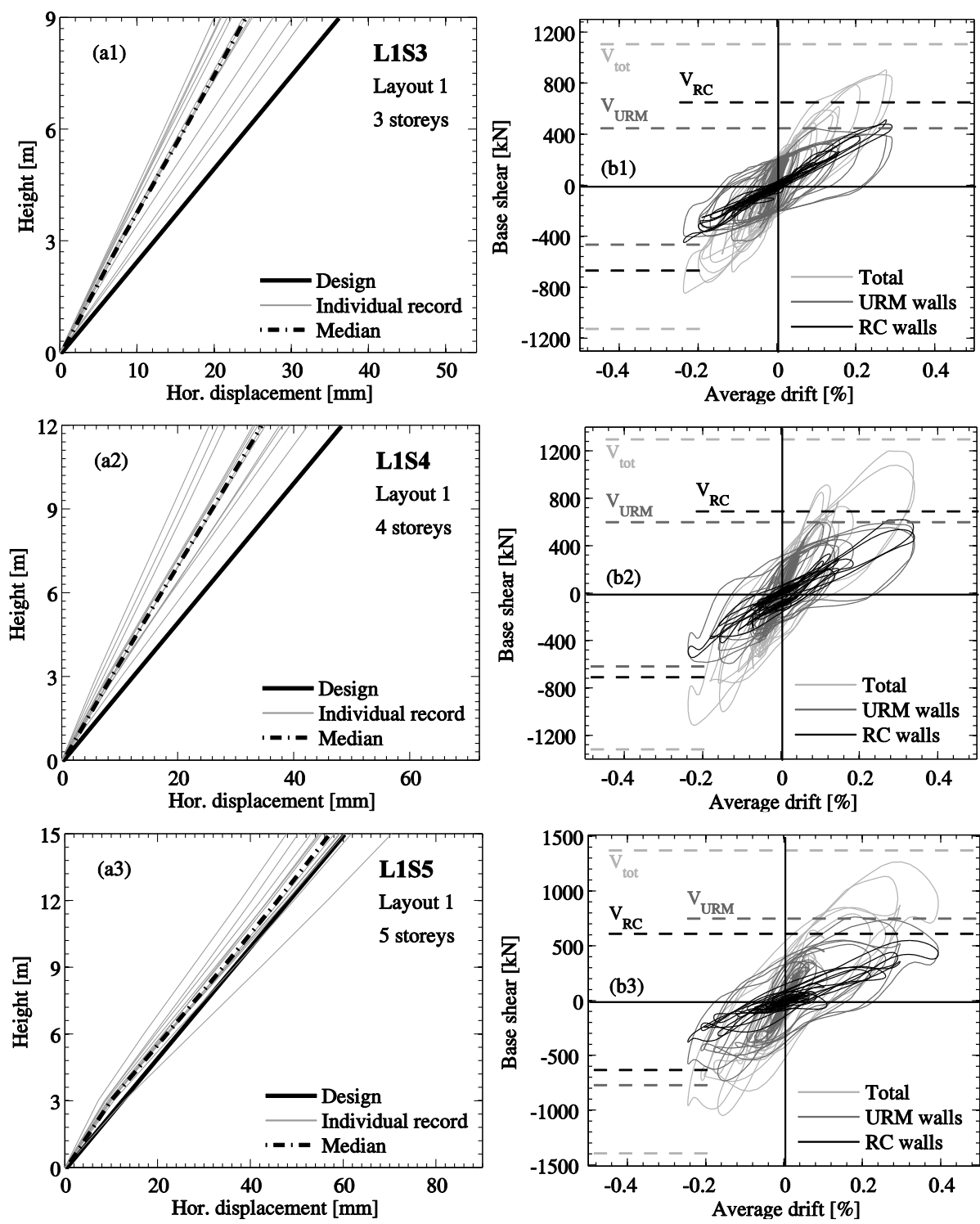

Fig. 17 Time-history response for wall layout 1 structures. Displacement profiles (a). Hysteretic behaviour of the structures subjected to record 12 and comparison against design values. $V_{R C}, V_{U R M}$, $V_{\text {tot }}$ : design shear forces for RC and URM walls and total design shear force (b) 
For Layouts 1 and 2 the design of the six storey structures has been carried out with the objective to check the performance of the design approach for structures in which $\xi_{U R M}$ is not affected by the period dependency (i.e., both initial and effective periods are in the linear branch of the displacement spectrum as $T_{i} \approx 0.6 \mathrm{~s}$ and $T_{e} \approx 1.0 \mathrm{~s}$ ). Fig. 19 confirms that, for the six storey configurations, the maximum displacement is rather well estimated by the design approach.
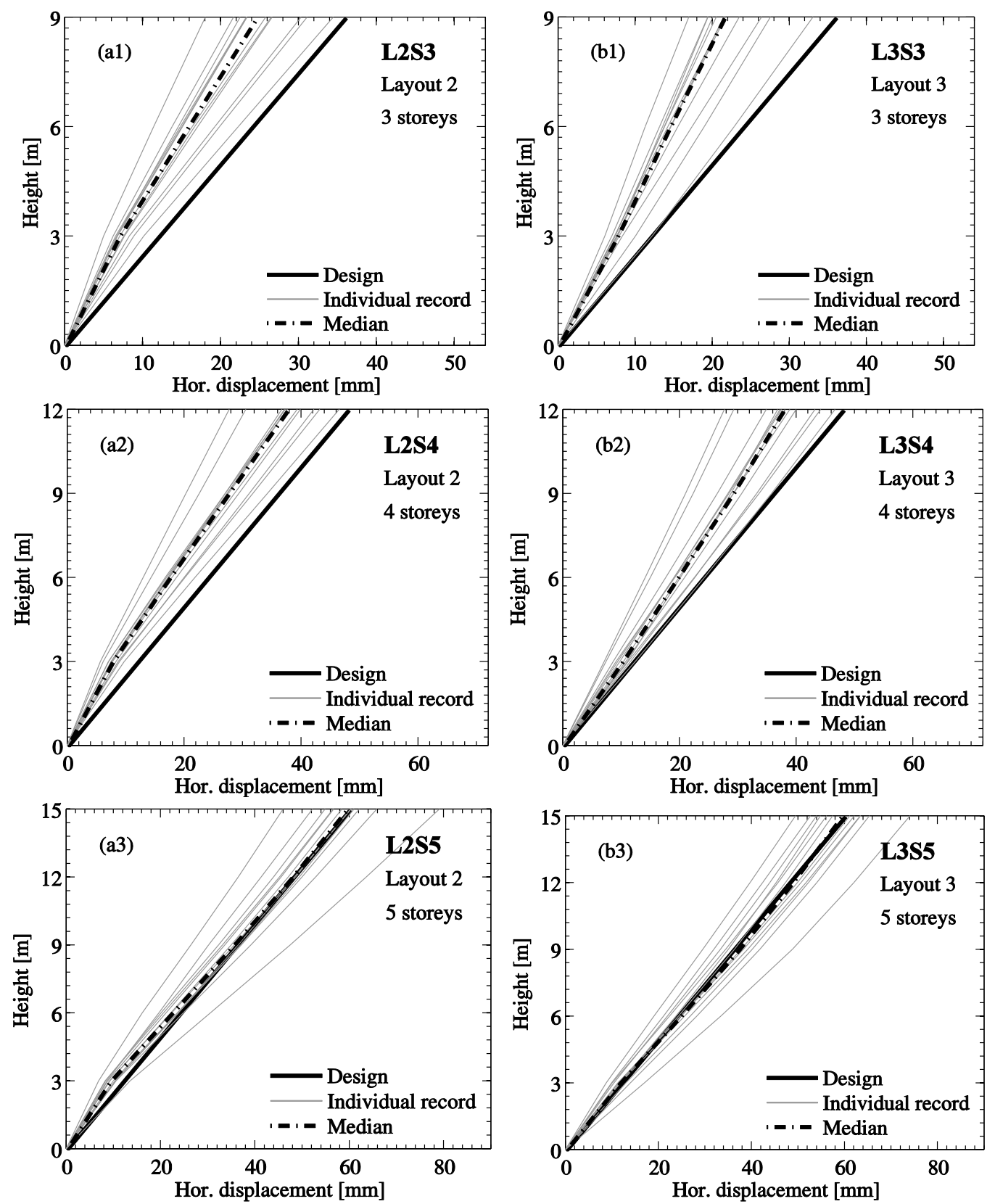

Fig. 18 Time-history response for wall layout 2 (a) and wall layout 3 structures (b). Displacement profiles 


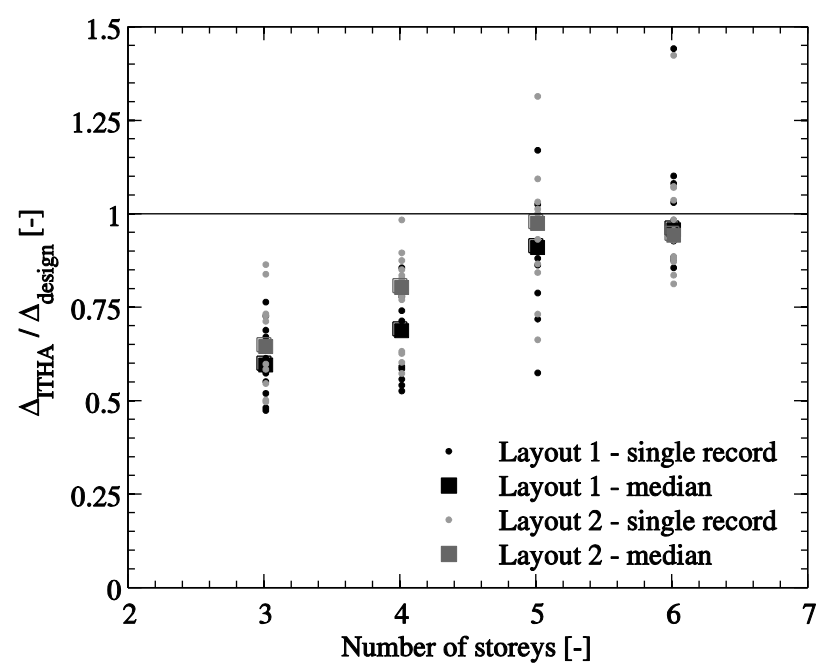

Fig. 19 Normalised top displacement recorded from ITHA with respect to the design top displacement $\Delta_{\text {ITHA }} / \Delta_{\text {design. }}$. Influence of the number of storeys

For wall layouts 1 (L1), the hysteretic behaviour obtained from one of the stationary accelerograms (record 12) is plotted, Fig. 17(b). The objective is to show the global hysteretic behaviour of the systems and the distribution of the base shear among RC and URM walls. The maximum base shear carried by the URM walls appears to be rather well estimated. At the same time, the design procedure overestimates the base shear carried by the RC walls up to $20 \%$. The hysteretic response of the URM walls confirms that the URM walls develop a dominant shear behaviour and that the values of $\xi_{\text {sys }}$ obtained from design approach (i.e., between 15\% and 25\%) are consistent with the results from the ITHA analyses.

\section{Conclusions}

Re-examinating the seismic hazard in Europe led, in particular for regions of low to moderate seismicity, to an increase in the seismic demand. As a result, in Switzerland many new residential buildings have been constructed using both RC and URM walls coupled together by RC slabs. Of late, also existing modern URM wall constructions with RC slabs, which no longer meet the requirements of the seismic design check, have been retrofitted by adding or replacing URM walls with concrete ones. Although this technique is rather common, codes do not provide guidelines for the design and assessment of such mixed structures.

The aim of this paper was therefore to propose a displacement-based design methodology for the seismic design of buildings in which the lateral bracing system consists of both RC and URM walls. The methodology follows the direct displacement-based design by Priestley et al. (2007). The design consists of three main phases: (i) A preliminary DDBD check of the plain URM building. (ii) If the structure does not satisfy the seismic design check and has a dominant shear behaviour, retrofitting the structure by replacing some URM walls by RC ones is a viable solution. (iii) In the final phase, the DDBD design of the mixed RC-URM wall structure is carried out. 
In the article, two tools for estimating important quantities relevant for the DDBD are proposed. (i) A simple mechanical model based on the shear-flexure wall interaction is implemented and validated. The objective is to provide a tool for estimating the deformed shape of the structure and the height of the contra-flexure point of the RC walls. Such a model was firstly developed to represent the shear-flexure interaction which arises in dual frame-wall buildings (e.g., Pozzati 1980). (ii) Furthermore, the contribution of the RC slabs to the overturning moment capacity is evaluated by elastic continuous beams. Connections between the slabs and the masonry walls are represented by vertical supports which work only in compression. The aim is to represent the limited capacity of the URM walls to equilibrate moments and shears transmitted by the RC slabs. Connections between slabs and RC walls are modelled instead by pins that can also transmit tension forces.

The DDBD methodology has been checked by designing several case studies and comparing their structural performance through ITHA. The design method effectively controlled the horizontal deflection of the structure, being almost linear over its height. Furthermore, it was observed that, particularly for the three storey configurations, the maximum displacement obtained from ITHA was lower than the design value. This difference is explained by the short effective period of the three storey configurations and how the period dependency of $\xi_{U R M}$ has been accounted for. A possible solution would be to correlate the inelastic displacement demand to the demand slope factor, which is a function of the elastic spectral displacement demand variation between the initial and the effective periods (Pennucci et al. 2011). Also the predicted magnitude of the shear forces carried by RC and URM walls was rather similar to the actual values obtained from ITHA.

\section{Acknowledgments}

The authors thank Chris Genis for proofreading the article.

\section{References}

Beyer, K., Tondelli, M., Petry, S. and Peloso, S. (2014), "Dynamic testing of a 4-storey building with reinforced concrete and unreinforced masonry walls", to be submitted to Bull. Earthq. Eng.

Cardone, D., Dolce, M. and Palermo, G. (2009), "Direct displacement-based design of seismically isolated bridges", Bull. Earthq. Eng., 7(2), 391-410.

Cattari, S. and Lagomarsino, S. (2013), "Seismic assessment of mixed masonry-reinforced concrete buildings by non-linear static analyses", Earthq. Struct., 4(3), 1-24.

Chiarugi, A. (1970), "Indagine sulla ripartizione delle azioni orrizzontali in telai irrigiditi da pareti", Giornale del Genio Civile, 2, 187-203.

EN 1992-1-1 (2004), Eurocode 2: Design of concrete structures - Part 1-1: General rules and rules for buildings, CEN, Brussels.

EN 1998-1 (2004), Eurocode 8: Design of structures for earthquake resistance - Part 1: General rules, seismic actions and rules for buildings, CEN, Brussels.

EN 1998-3 (2005), Eurocode 8: Design of structures for earthquake resistance - Part 3: Assessment and retrofitting of buildings, CEN, Brussels.

Graziotti, F. (2013), "Contribution towards a displacement-based seismic assessment of masonry structures", Pavia, Italy. 
Hannenwald, P. (2013), "Seismic behaviour of poorly detailed RC bridge piers" Ph.D. thesis, EPFL, Lausanne, Switzerland.

Lagomarsino, S., Penna, A., Galasco, A. and Cattari, S. (2013), “TREMURI program: An equivalent frame model for the nonlinear seismic analysis of masonry buildings”, Eng. Struct., 56, 1787-1799.

Lang, K. (2002), "Seismic vulnerability of existing buildings", Ph.D. Dissertation, ETH Zurich, Switzerland.

Magenes, G. (2006), "Masonry building design in seismic areas: recent experiences and prospects form and European standpoint", Keynote address, Proceedings of the 1st European Conference on Earthquake Engineering and Seismology, Geneva, Switzerland.

Mandirola, M. (2014), "Non-linear macroelement modelling of experimental tests on masonry building specimens with rigid diaphragms", Pavia, Italy.

Mann, W. and Muller, H. (1982), "Failure of shear-stressed masonry: an enlarged theory, tests and application to shear walls“, Proceedings of British Ceramic Society, Stoke-on-Trent, Great Britain.

Michel, C., Lestuzzi, P. and Lacave, C. (2014), "Simplified non-linear seismic displacement demand prediction for low period structures", Bull. Earthq. Eng., 12(4), 1972-1998.

Paparo, A. and Beyer, K. (2014), "Quasi-static tests of two mixed reinforced concrete - unreinforced masonry wall structures”, Eng. Struct., 71, 201-211.

Paparo, A. and Beyer, K. (2015), "Modelling the seismic response of modern URM buildings retrofitted by adding RC walls", J. Earthq. Eng., in press.

Paulay, T. and Priestley, M.N.J. (1992), Seismic design of reinforced concrete and masonry buildings, John Wiley \& Sons, Inc., New York.

Penna, A., Lagomarsino, S. and Galasco, A. (2013), "A nonlinear macro-element model for the seismic analyses of masonry buildings", Earthq. Eng. Struct. Dyn., doi:10.1002/eqe.2335.

Pennuci, D., Calvi, G.M. and Sullivan, T.J. (2009), "Displacement-based design of pre-cast walls with additional dampers", J. Earthq. Eng., 13(S1), 40-65.

Pennucci, D., Sullivan, T.J. and Calvi, G.M. (2011), "Displacement reduction factors for the design of medium and long period structures", J. Earthq. Eng., 13(S1), 1-29.

Pozzati, P. (1980), Teoria e tecnica delle structuure, UTET, Torino.

Priestley, M.J.N. (1993), "Myths and fallacies in earthquake engineering - conflicts between design and reality", Bull. NZ Natl. Soc. Earthq. Eng., 26(3), 329-341.

Priestley, M.J.N. (1998), "Direct displacement-based design of buildings", Proceedings of the $11^{\text {th }}$ European Conference on Earthquake Engineering, Paris, France.

Priestley, M.J.N., Calvi, G.M. and Kowalsky, M.J. (2007), Displacement-Based Seismic Design of Structures, IUSS Press, Pavia.

Rosman, R. (1967), “Laterally loaded systems consisting of walls and frames”, Tall Build., 291-320.

Rosman, R. (1974), "Stability and dynamics of shear-wall frame structures", Build. Sci., 9(1), 55-63.

SIA 262 (2004), Building code, Swiss Society of Engineers and Architects (SIA): Concrete Structures, SIA, Zurich.

Smith, B.S. and Coull, A. (1991), Tall building structures: analysis and design, John Wiley \& Sons, Inc., New York.

Sullivan, T.J., Priestley, M.J.N. and Calvi, G.M. (2005), "Development of an innovative seismic design procedure for frame-wall structure",k J. Earthq. Eng., 9(2), 279-307.

Sullivan, T.J., Priestley, M.J.N. and Calvi, G.M (2006), "Direct displacement-based design of frame-wall structures", J. Earthq. Eng., 10(1), 91-124.

Sullivan, T.J., Priestley, M.J.N. and Calvi, G.M. (2012), A Model Code for the Displacement-Based Seismic Design of Structures, IUSS Press, Pavia.

Tondelli, M. and Beyer, K. (2014), "Observations on out-of-plane behaviour of URM walls in buildings with RC slabs", Proceedings of the $9^{\text {th }}$ International Masonry Conference, Guimaraes, Portugal. 


\section{APPENDIX: Design example}

To illustrate the procedure, the DDBD of L1S5 (wall layout 1, 5 storeys) is presented. The methodology is iterative and stops when the variation of the required strength of the RC wall $\left(M_{R C r e q}\right)$ between two steps is smaller than 5\%. The structure is located in a moderate seismicity area and the seismic demand is represented by an acceleration design spectrum of soil class $\mathrm{C}$ $\left(T_{B}=0.2 \mathrm{~s} ; T_{C}=0.6 \mathrm{~s}\right.$ and $T_{D}=2 \mathrm{~s}$ (EN 1998-1 2004)) with PGA equal to $0.25 \mathrm{~g}$ (Fig. 16). The design drift $\delta_{d}$, associated with the SD limit state for URM walls failing in shear, is set equal to $0.4 \%$ (EN 1998-3 2005). Assuming further a constant inter-storey drift over the height of the structure, the SD limit state is therefore reached if the average drift corresponds to $0.4 \%$.

The RC wall is designed to exhibit a displacement ductility $\mu_{\triangle R C}$ equal to 1.2 . The axial force acting at the base of each wall is $500 \mathrm{kN}$ and corresponds to an axial stress ratio at the base of the masonry walls $\left(\sigma_{\sigma} / f_{m}\right)$ of $8.8 \%$. The mass whose weight is carried by walls in the direction of excitation $(m \|)$ is equally distributed between RC and URM walls, resulting in masses of $10.2 \mathrm{t}$ applied at the top of the centrelines of each wall. An additional mass $(m \perp)$ equal to $m \|$ is added with a flexible frame and simulates the weight carried by the walls perpendicular to the

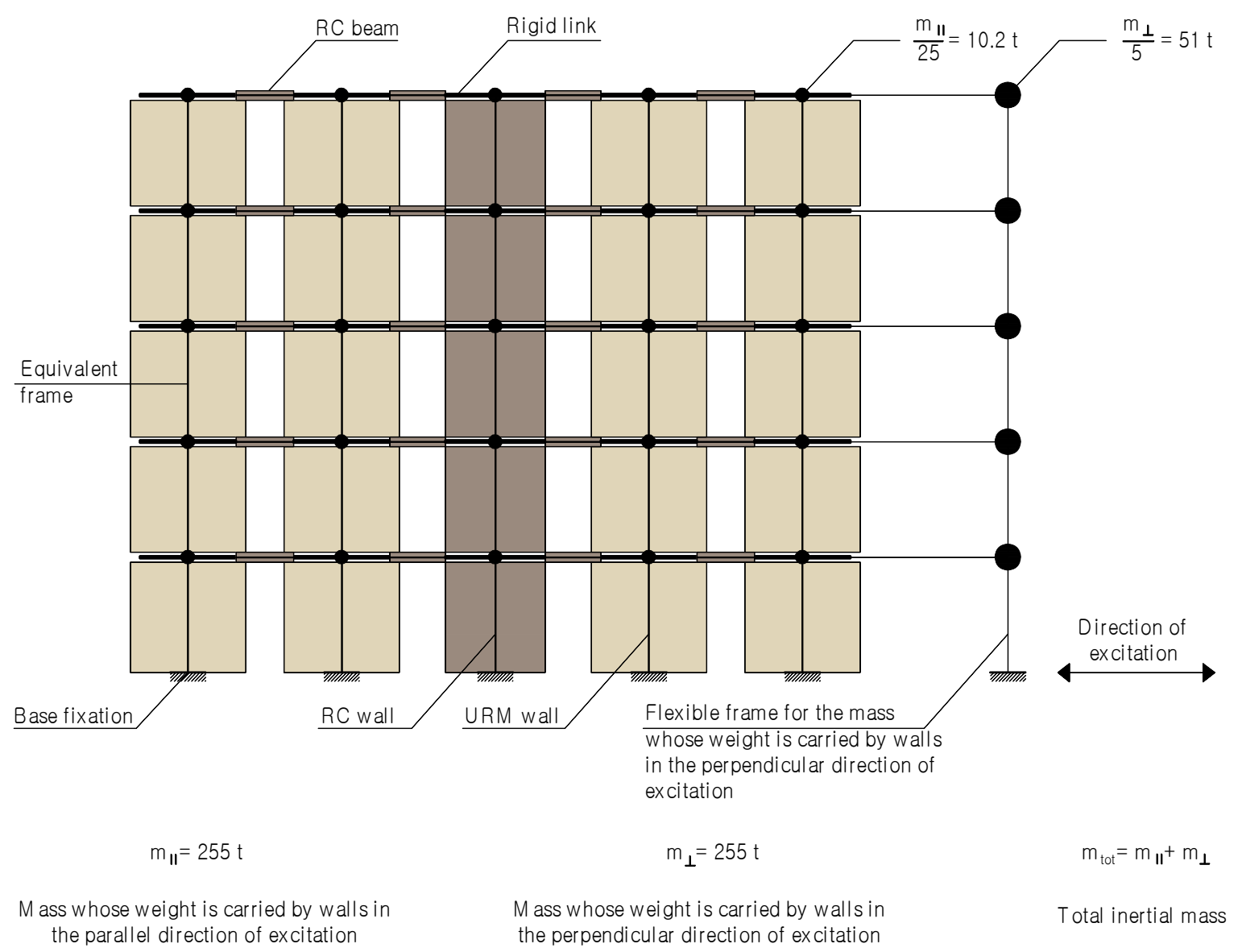

Fig. 20 TREMURI model used for ITHA 
direction of excitation (Fig. 20). It results that the total inertial mass $\left(m_{t o t}=m \|+m \perp\right)$ is $510 \mathrm{t}$ while the gravity load carried by the walls in the direction of excitation $(m \|)$ is 255 t. Additional information on the structure is provided in Section 7.1.

\section{A - Preliminary design check of the plain URM wall building}

The design starts by checking the plain URM wall structure with RC slabs. Firstly, it has to be verified that the displacement capacity of the URM building $\left(\Delta_{\text {cap }}\right)$ is smaller than the displacement demand $\left(\Delta_{d e m}\right)$. This check is carried out by following the displacement-based assessment approach proposed by Priestley et al. (2007). The procedure requires the knowledge of the displacement capacity $\left(\Delta_{\text {cap }}\right)$ and the effective mass $\left(m_{e}\right)$ of the structure. The displacement capacity $\left(\Delta_{\text {cap }}\right)$, which corresponds to the design displacement $\left(\Delta_{d}\right)$, and the effective mass $\left(m_{e}\right)$ are calculated by assuming a design deformed shape that concentrates the deformations in the lowest storey (Table 5 and Fig. 21a). From Eqs. (12) to (14) results as follows

$$
\begin{gathered}
\Delta_{\text {cap }}=\Delta_{d}=\frac{\sum m_{i} \Delta_{i}^{2}}{\sum m_{i} \Delta_{i}}=\frac{0.073}{6.11}=0.012 \mathrm{~m} \\
m_{e}=\frac{\sum m_{i} \Delta_{i}}{\Delta_{d}}=\frac{6.11}{0.012}=510 t
\end{gathered}
$$

The procedure is iterative and continues by guessing the displacement demand $\left(\Delta_{d e m}\right)$, whose value is revised in the iterations. Furthermore, the knowledge of the equivalent viscous damping (here assumed equal to 0.31$)$ and the shear strength capacity of the building $\left(V_{t o t}\right)$ are required. The latter is calculated according to Mann and Müller (1982)

$$
V_{\text {tot }}=0.38 N_{U R M}=0.38 x(5 \times 500)=950 \mathrm{kN}
$$

At each iteration, the effective stiffness $K_{e}$ and the effective period $T_{e}$ are calculated. From $T_{e}$ the new displacement demand is determined from the over-damped spectra. Table 6 summarises the main outputs of each iteration. The procedure is stopped when the displacement demand varies less than 5\% from one step to the other. From the calculations the structure does not satisfy the design check as the displacement demand is higher than the displacement capacity: $\Delta_{\text {dem }}>\Delta_{\text {cap }}$.

Table 5 Single degree of freedom simulation of the pain URM wall structure

\begin{tabular}{cccccccccc}
\hline \hline Storey & $\boldsymbol{H}_{\boldsymbol{i}}$ & $\boldsymbol{m}_{\boldsymbol{i}}$ & $\boldsymbol{\delta}_{\boldsymbol{d}}$ & $\boldsymbol{\Delta}_{\boldsymbol{i}}=\boldsymbol{\delta}_{\boldsymbol{d}} \boldsymbol{H}_{\boldsymbol{i}}$ & $\boldsymbol{\Delta}_{\boldsymbol{i}}{ }^{2}$ & $\boldsymbol{H}_{\boldsymbol{i}} \boldsymbol{\Delta}_{\boldsymbol{i}}$ & $\boldsymbol{m}_{\boldsymbol{i}} \boldsymbol{\Delta}_{\boldsymbol{i}}$ & $\boldsymbol{m}_{\boldsymbol{i}} \boldsymbol{\Delta}_{\boldsymbol{i}}{ }^{2}$ & $\boldsymbol{m}_{\boldsymbol{i}} \boldsymbol{\Delta}_{\boldsymbol{i}} \boldsymbol{H}_{\boldsymbol{i}}$ \\
\hline$[-]$ & {$[\mathrm{m}]$} & {$[\mathrm{t}]$} & {$[\%]$} & {$[\mathrm{m}]$} & {$\left[\mathrm{m}^{2}\right]$} & {$\left[\mathrm{m}^{2}\right]$} & {$[\mathrm{tm}]$} & {$\left[\mathrm{tm}^{2}\right]$} & {$\left[\mathrm{tm}^{2}\right]$} \\
\hline 1 & 3 & 102 & 0.40 & 0.012 & 0.00014 & 0.036 & 1.224 & 0.015 & 3.67 \\
2 & 6 & 102 & 0.00 & 0.012 & 0.00014 & 0.072 & 1.224 & 0.015 & 7.34 \\
3 & 9 & 102 & 0.00 & 0.012 & 0.00014 & 0.108 & 1.224 & 0.015 & 11.02 \\
4 & 12 & 102 & 0.00 & 0.012 & 0.00014 & 0.144 & 1.224 & 0.015 & 14.69 \\
5 & 15 & 102 & 0.00 & 0.012 & 0.00014 & 0.180 & 1.224 & 0.015 & 18.36 \\
Sum & - & 510 & & 0.060 & 0.00072 & 0.540 & 6.120 & 0.073 & 55.08 \\
\hline
\end{tabular}

$H_{i}=$ storey height

$m_{i}=$ total storey mass 
$\delta_{d}=$ design drift

$\Delta_{i}=$ horizontal storey displacement

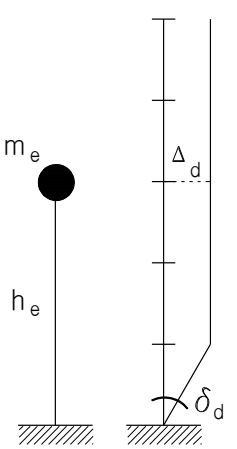

URM building

(a)

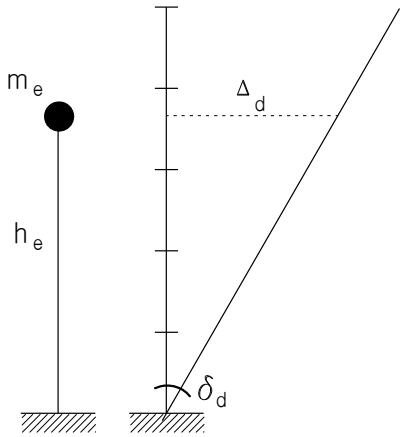

Mixed system

(b)

Fig. 21 Assumed displacement profile and SDOF simulations for the URM building and the mixed system

Additionally, it has to be verified that the URM walls are developing a shear rather than a flexural mechanism: $M_{U R M, s h}<M_{U R M, f l}$. To simplify matters, no variation of axial force at the base of the masonry walls due to coupling of the slabs is assumed. $M_{U R M, s h}$ can be computed (Eqs. (24) to (26))

$$
M_{U R M, s h}=V_{s h} H_{C F, U R M}=(0.38 x N)\left(\frac{h_{s t}}{2} \gamma \psi\right)=(0.38 \times 500)\left(\frac{3.0}{2} x 1.5 x 1\right)=430 \mathrm{kNm}
$$

$N$ is the total axial force at the base of the considered URM wall. $M_{U R M, f l}$ can be computed according to EN 1998-3 (2005)

$$
M_{U R M, f l}=\frac{N l_{U R M}}{2}\left(1-1.15 \frac{N}{l_{U R M} t f_{m}}\right)=\frac{500 \times 3}{2}\left(1-1.15 \frac{0.50}{3 \times 0.3 \times 6.3}\right)=675 \mathrm{kNm}
$$

With $l_{U R M}$ and $t_{U R M}$ the length and thickness of the wall and $f_{m}$ the masonry compressive strength. As $M_{U R M, S h}>M_{U R M, f l}$, the masonry building has a dominant shear rather than flexural behaviour.

Table 6 Iterative displacement-based assessment procedure of the plain URM building

\begin{tabular}{cccc}
\hline \hline Iteration & $\boldsymbol{\Delta}_{\text {dem }}$ & $\boldsymbol{K}_{\boldsymbol{e}}$ & $\boldsymbol{T}_{\boldsymbol{e}}$ \\
\hline$[-]$ & {$[\mathrm{m}]$} & {$[\mathrm{kN} / \mathrm{m}]$} & {$[\mathrm{s}]$} \\
\hline 0 & 0.018 & 53000 & 0.61 \\
1 & 0.027 & 35200 & 0.76 \\
2 & 0.033 & 28800 & 0.83 \\
3 & 0.036 & 26400 & 0.87 \\
4 & 0.038 & 25000 & 0.89 \\
5 & 0.039 & - & - \\
\hline
\end{tabular}


$\Delta_{\text {dem }}=$ displacement demand

$K_{e}=$ effective stiffness $\left(K_{e}=V_{\text {tot }} / \Delta_{\text {dem }}\right)$

$T_{e}=\operatorname{effective} \operatorname{period}\left(T_{e}=2 \pi \sqrt{m_{e} / K_{e}}\right)$

The starting, guessed, value of the displacement demand is underlined

Table 7 Single degree of freedom simulation of the mixed RC-URM wall structure

\begin{tabular}{cccccccccc}
\hline \hline Storey & $\boldsymbol{H}_{\boldsymbol{i}}$ & $\boldsymbol{m}_{\boldsymbol{i}}$ & $\boldsymbol{\delta}_{\boldsymbol{d}}$ & $\boldsymbol{\Delta}_{\boldsymbol{i}}=\boldsymbol{\delta}_{\boldsymbol{d}} \boldsymbol{H}_{\boldsymbol{i}}$ & $\boldsymbol{\Delta}_{\boldsymbol{i}}^{\mathbf{2}}$ & $\boldsymbol{H}_{\boldsymbol{i}} \boldsymbol{\Lambda}_{\boldsymbol{i}}$ & $\boldsymbol{m}_{\boldsymbol{i}} \boldsymbol{\Lambda}_{\boldsymbol{i}}$ & $\boldsymbol{m}_{\boldsymbol{i}} \boldsymbol{\Delta}_{\boldsymbol{i}}{ }^{2}$ & $\boldsymbol{m}_{\boldsymbol{i}} \boldsymbol{\Delta}_{\boldsymbol{i}} \boldsymbol{H}_{\boldsymbol{i}}$ \\
\hline$[-]$ & {$[\mathrm{m}]$} & {$[\mathrm{t}]$} & {$[\%]$} & {$[\mathrm{m}]$} & {$\left[\mathrm{m}^{2}\right]$} & {$\left[\mathrm{m}^{2}\right]$} & {$[\mathrm{tm}]$} & {$\left[\mathrm{tm}^{2}\right]$} & {$\left[\mathrm{tm}^{2}\right]$} \\
\hline 1 & 3 & 102 & 0.40 & 0.012 & 0.0001 & 0.036 & 1.224 & 0.015 & 3.67 \\
2 & 6 & 102 & 0.40 & 0.024 & 0.0006 & 0.144 & 2.448 & 0.059 & 14.69 \\
3 & 9 & 102 & 0.40 & 0.036 & 0.0013 & 0.324 & 3.672 & 0.132 & 33.05 \\
4 & 12 & 102 & 0.40 & 0.048 & 0.0023 & 0.576 & 4.896 & 0.235 & 58.75 \\
5 & 15 & 102 & 0.40 & 0.060 & 0.0036 & 0.900 & 6.120 & 0.367 & 91.80 \\
Sum & - & 510 & & 0.180 & 0.0079 & 1.980 & 18.36 & 0.808 & 201.96 \\
\hline
\end{tabular}

$H_{i}=$ storey height

$m_{i}=$ total storey mass

$\delta_{d}=$ design drift

$\Delta_{i}=$ horizontal storey displacement

As the structure $(i)$ does not satisfy the design requirement $\left(\Delta_{\text {cap }}<\Delta_{\text {dem }}\right)$ and (ii) has a dominant shear behaviour $\left(M_{U R M, s h}<M_{U R M, f l}\right)$, replacing a URM wall by a RC wall is a viable retrofit solution. It is decided to replace the central masonry pier with one RC wall, Fig. 23(b).

$\underline{B}$ - Design displacement and SDOF simulation of the mixed RC-URM wall structure

For the SDOF simulation of the mixed RC-URM wall structure, the assumed design deformed shape is linear (Table 7 and Fig. 21b). From Eqs. (12) to (14) $\Delta_{d}, m_{e}$ and $h_{e}$ are obtained

$$
\begin{gathered}
\Delta_{d}=\frac{\sum m_{i} \Delta_{i}^{2}}{\sum m_{i} \Delta_{i}}=\frac{0.808}{18.36}=0.044 m \\
m_{e}=\frac{\sum m_{i} \Delta_{i}}{\Delta_{d}}=\frac{18.36}{0.044}=417 t \\
h_{e}=\frac{\sum m_{i} \Delta_{i} H_{i}}{\sum m_{i} \Delta_{i}}=\frac{202}{18.36}=11 \mathrm{~m}
\end{gathered}
$$

$C$ - Contribution to the overturning moment provided by the URM walls ( $\left.M_{U R M}\right)$

The strength capacity of the URM walls $\left(V_{s h}\right)$ is calculated according to Mann and Müller (1982) and $M_{U R M}$ is estimated from Eqs. (24) to (27) as follows: 


$$
\begin{gathered}
V_{s h}=0.38 N_{U R M}=0.38 x(4 \times 500)=760 \mathrm{kN} \\
\gamma=1+n / 10=1+5 / 10=1.5 \\
\psi=h_{s t} / l_{U R M}=1 \\
M_{U R M}=V_{s h} H_{C F, U R M}=V_{s h}\left(\frac{h_{s t}}{2} \gamma \psi\right)=760\left(\frac{3}{2} x 1.5 \times 1\right)=1710 \mathrm{kNm}
\end{gathered}
$$

\section{$D$-Iterative procedure to find the required strength and the length of the $R C$ wall}

\section{Iteration 0 (starting values)}

Initially, to calculate the damping reduction factor $\eta_{\xi}$ (Eq. (15)) and the overturning moment demand (Eqs. (16), (17), (22)), the equivalent viscous damping is assumed equal to $20 \%$

$$
\begin{gathered}
\xi_{\text {sys }}=20 \% \rightarrow \eta_{\xi}=\left(\frac{0.07}{0.02+\xi_{\text {sys }}}\right)^{0.5}=0.564 \\
K_{e}=\frac{4 \pi^{2} m_{e}}{T_{e}^{2}}=\frac{4 x 3.14^{2} \times 417}{0.82^{2}}=24400 \mathrm{kN} / \mathrm{m} \\
V_{\text {base }}=K_{e} \Delta_{d}=24400 x 0.044=1070 \mathrm{kN} \\
O T M_{\text {dem }}=V_{\text {base }} h_{e}=1070 x 11=11820 \mathrm{kNm}
\end{gathered}
$$

The yield rotation of the RC slabs flanking the RC walls, $\theta_{y s}$, is calculated according to Eq. (30). As the dimensions of the $\mathrm{RC}$ walls are unknown, a trial length of $3.0 \mathrm{~m}$ is assumed

$$
l_{R C}=3.0 \rightarrow L_{s e}=L_{s}+h_{s}=1.00+0.25=1.25 m \rightarrow \theta_{y s}=0.35 \varepsilon_{y} \frac{L_{s}}{h_{s}}=0.48 \%
$$

$\varepsilon_{y}$, the yield strain of the longitudinal bars of the RC wall, is calculated from the yield stress and the E-modulus of the reinforcing bars

$$
\varepsilon_{y}=\frac{f_{y}}{E}=\frac{550}{200000}=0.00275
$$

The rotation demand is found by assuming for the URM walls rigid body rotations around the base corner in compression and for the $\mathrm{RC}$ wall a rigid body rotation around its centreline (Fig. 22)

$$
\Delta_{V 2 r}=0 m m
$$




$$
\begin{gathered}
\Delta_{V R C}=\delta_{d} \frac{L_{R C}}{2}=0.4 \% \frac{3.0}{2}=+6 \mathrm{~mm} \\
\Delta_{V R C}=-\Delta_{V R C}=-6 \mathrm{~mm} \\
\Delta_{V 3 l}=\delta_{d} L_{U R M 3}=0.4 \% \times 3.0=+12 \mathrm{~mm} \\
\theta_{s 2}=\frac{\Delta_{V 2 r}+\Delta_{V R C r}}{L_{s e}}=\frac{0+6}{1000}=0.6 \% \\
\theta_{s 3}=\frac{-\Delta_{V R C}+\Delta_{V 3 l}}{L_{s e}}=\frac{6+12}{1000}=1.8 \%
\end{gathered}
$$

As the structure is symmetric, the mean rotation demand $\theta_{s}=\left(\theta_{s 2}+\theta_{s 3}\right) / 2=1.2 \%$ is used for calculating the bending moment applied to the pins connecting the slabs to the RC walls $\left(M_{s, w}\right)$.

As $\theta_{s}>\theta_{y s}, M_{s, w}=M_{y s, w}=110 \mathrm{kNm}$, Eq. (31a). The contribution to the overturning moment from the RC slabs, $M_{S}$, is then calculated by using elastic continuous beams. According to Eq. (28), $M_{S}$ is the sum of the contributions of the different bays $\left(M_{b a y, j}\right)$

$$
M_{S}=M_{b a y 1}+M_{b a y 2}+M_{b a y 3}+M_{b a y 4}=7970 \mathrm{kNm}
$$

The reaction forces of supports and pins of the elastic continuous beams are represented in Fig. 24. Note that the vertical supports between URM walls and slabs are all working in compression while some pins connecting $\mathrm{RC}$ walls and slabs transmit tension forces.

It is then possible to calculate the required strength of the RC wall (Eq. (36))

\begin{tabular}{|c|c|c|c|c|c|c|c|c|}
\hline Iteration & IRC & छsys & OTMdem & MS & MRCreq & VRCreq & $\beta R$ & $\alpha$ \\
\hline$[-]$ & {$[\mathrm{m}]$} & {$[\%]$} & {$[\mathrm{kNm}]$} & {$[\mathrm{kNm}]$} & {$[\mathrm{kNm}]$} & {$[\mathrm{kN}]$} & {$[\%]$} & {$[-]$} \\
\hline 0 & 3.00 & 20.0 & 11820 & 7970 & 2140 & 630 & 18 & 3.5 \\
\hline 1 & 2.53 & 21.0 & 11310 & 7180 & 2420 & 640 & 21 & 3.1 \\
\hline 2 & 2.75 & 20.8 & 11410 & 7530 & 2170 & 630 & 19 & 3.4 \\
\hline 3 & 2.60 & 21.1 & 11260 & 7285 & 2264 & 620 & 20 & 3.3 \\
\hline 4 & 2.66 & - & - & - & - & - & - & - \\
\hline
\end{tabular}

$$
M_{R C r e q}=O T M_{d e m}-M_{S}-M_{U R M}=11820-7970-1710=2140 \mathrm{kNm}
$$

\section{Iterations 1 to 4}

The iterations continue until the variation of the strength of the RC wall $M_{R C r e q}$ between two steps is smaller than $5 \%$. Table 8 summarises the main DDBD outputs of each iteration.

Table 8 Iterative procedure

$l_{R C}=$ length of the $R C$ wall

$\xi_{\text {sys }}=$ equivalent viscous damping of the system 
OTM $M_{\text {dem }}=$ overturning demand

$M_{S}=$ contribution to the overturning moment from the slabs

$M_{R C r e q}=$ required moment of the $R C$ wall

$V_{R C r e q}=$ required shear of the $R C$ wall

$\beta_{R C}=$ ratio of the contribution of the overturning moment from the $R C$ wall $\alpha=(G A / E I) 0.5$

Starting values are underlined

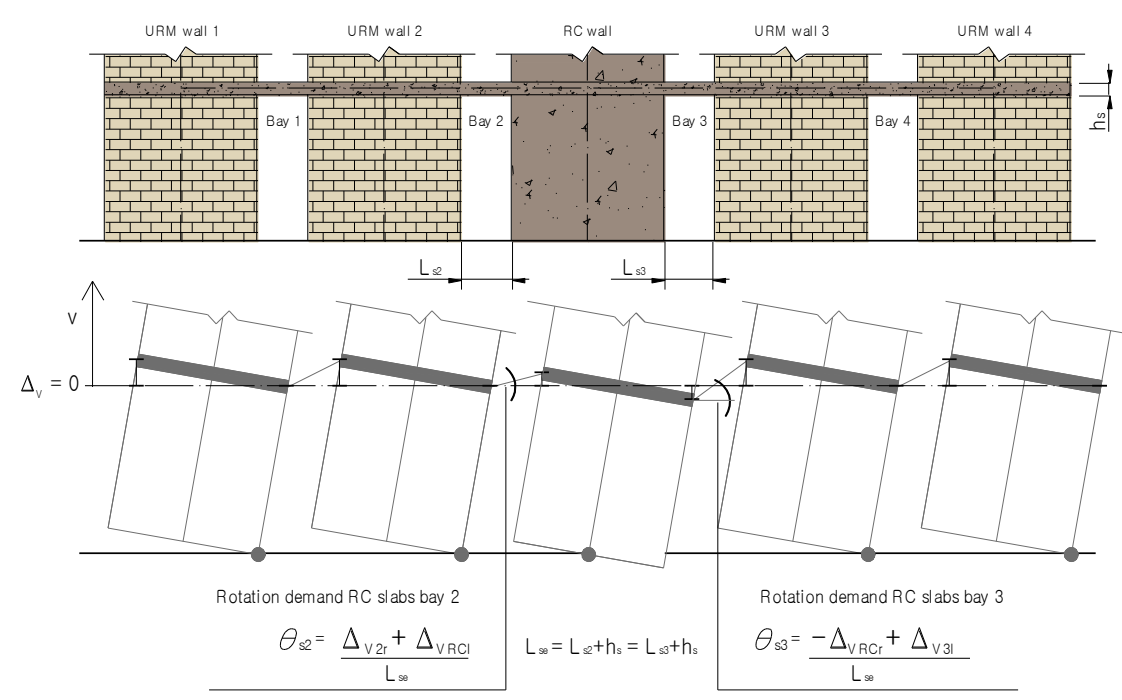

Fig. 22 Mechanism for calculating the rotation demands $\theta_{b 2}$ and $\theta_{b 3}$

(a)

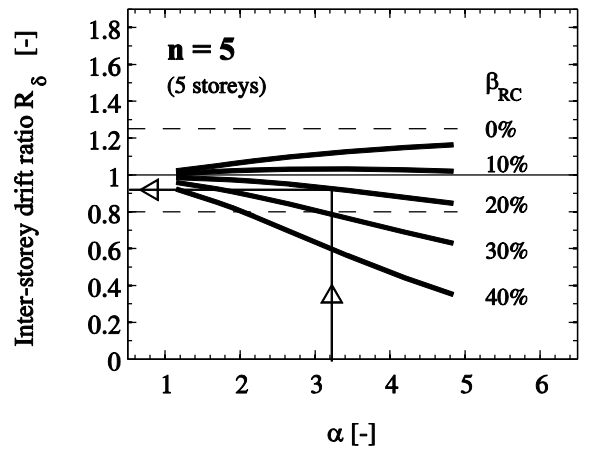

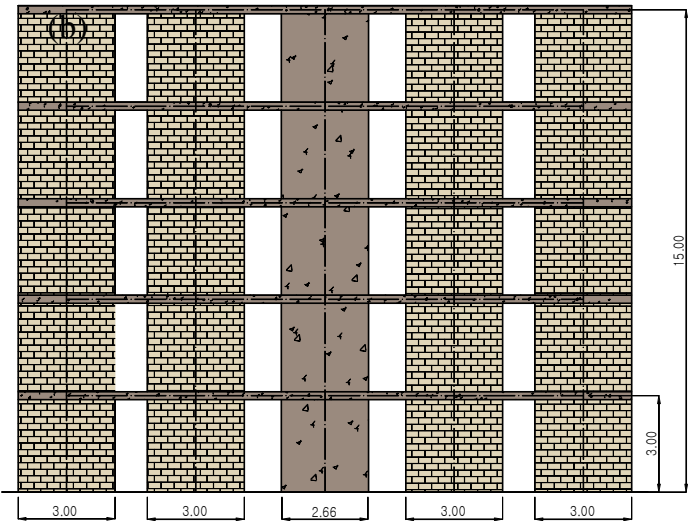

Fig. 23 Verification of the displacement profile of the structure (a). Final configuration of the mixed RC-URM wall structure. All dimensions in $\mathrm{cm}(\mathrm{b})$

\section{E-Ascertain the displacement profile of the structure}

Once length and strength of the RC wall are defined, the displacement profile of the structure is checked. With the design outputs $n=5, \beta_{R C}=20 \%$ and $\alpha=3.3$, the drift ratio $R_{\delta}$ is equal to around 0.9 , 
Fig. 23(a). As the assumption of the linear displacement profile is satisfied, the RC elements are designed, the out-of-plane requirements checked and the procedure is completed. If Eq. (11) is not respected, the designer has two options: (i) to choose a different number of URM walls to be replaced by the RC ones or (ii) to change the level of ductility of the RC wall. Fig. 23(b) represents the final structural configuration.
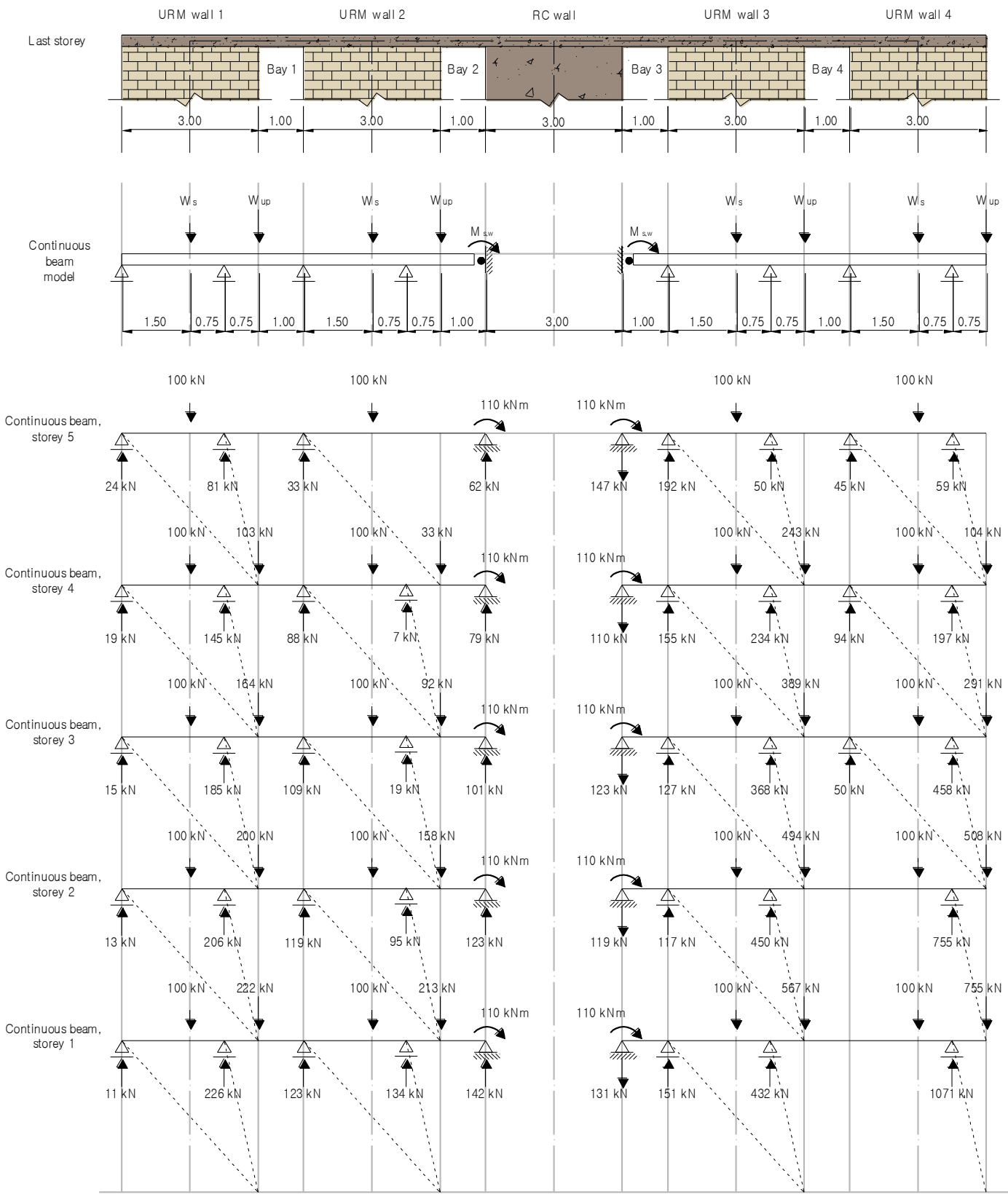

Fig. 24 Elastic continuous beams used for calculating $M_{S}$. All dimensions in $\mathrm{m}$ 